\title{
Una tipología de precariedad laboral para Chile: la precariedad como fenómeno transclasista ${ }^{1}$
}

\author{
Osvaldo Blanco y Dasten Julián
}

\section{Resumen}

Este artículo presenta una propuesta de definición y medición de la precariedad laboral. Comenzamos relacionando el fenómeno de la precariedad con las transformaciones de las fisonomías del trabajo y de las clases sociales. Luego, se expone una metodología que combina las técnicas del análisis de correspondencias y el clúster de k-medias para elaborar una tipología de nueve grupos de precariedad. Esto permite evidenciar la precariedad como un fenómeno multidimensional que articula aspectos ligados a la estabilidad, inseguridad, ingresos, condiciones de trabajo y jornadas laborales. Los resultados muestran que estaríamos frente a un fenómeno que no está vinculado a una única clase o posición dentro del mercado laboral, ni tampoco a una única dimensión o indicador, sino más bien a un proceso multidimensional y transclasista, que atraviesa fluidamente diferentes posiciones y situaciones a lo largo de la estructura ocupacional chilena.

\section{Palabras clave}

Empleo, condiciones de trabajo, política de empleo, contratos de trabajo, horas de trabajo, medición, clases sociales, Chile

\section{Clasificación JEL}

A14, J, J01, J81

\section{Autores}

Osvaldo Blanco Sepúlveda es Doctor en Sociología de la Universidad Alberto Hurtado (Chile), es Director del Diplomado en Gestión de Datos Estadísticos para la Intermediación Laboral de la Facultad de Economía y Negocios de la Universidad Andrés Bello de Viña del Mar (Chile). Correo electrónico: o.blancosepulveda@uandresbello.edu.

Dasten Alfonso Julián Vejar es Doctor en Sociología de la Universidad Friedrich Schiller de Jena (Alemania). Es académico e investigador del Departamento de Sociología y Ciencia Política de la Universidad Católica de Temuco (Chile). Correo electrónico: dasten@gmail.com.

\footnotetext{
1 Este artículo se inscribe en el marco del Proyecto FONDECYT Regular núm. 1161347 (2016-2019) Cartografía de la(s) precariedad(es) laboral(es) y las relaciones laborales de la Zona Centro Sur de Chile. Tipología del Trabajo Precario y su incidencia en la práctica sindical en las regiones del Maule, Biobío y La Araucanía", CONICYT (Chile). Los autores agradecen a dos evaluadores anónimos que comentaron la primera versión de este texto y los eximen de toda responsabilidad en esta versión final.
} 


\section{Introducción}

Cada vez parece más frecuente encontrarse con el concepto de "precariedad" en distintos contextos y en distintas referencias al campo de las ciencias sociales. Con el propósito de fijar algunos criterios de análisis, en el presente artículo se buscará dar cuenta de una aproximación multidimensional de la precariedad que recoja aspectos diversos ligados a las fisonomías de las relaciones contractuales, a la seguridad previsional y de salud, a los ingresos, las condiciones de trabajo y las jornadas laborales. La precariedad significaría no tanto ocupar un lugar o configurar una única clase o sujeto, sino más bien daría cuenta de una situación múltiple y fluida de fisonomías y debilidades ligadas a las transformaciones profundas que han vivido los mercados laborales, las relaciones de producción y las formas de acumulación. Siguiendo esta premisa, nuestro propósito es llenar la falta de propuestas de generación de perfiles laborales desde el enfoque de la precariedad.

Pretendemos contribuir al debate sobre la precariedad como concepto que da cuenta de un telón de fondo general ligado a las transformaciones del capitalismo y del mundo del trabajo, logrando posicionarse en la literatura relativa a la sociología del trabajo y de las ciencias sociales. En ese sentido, la precariedad forma parte de la recomposición de la sociología del trabajo, como concepto que reordena (y supera) el debate de la crisis y supuesto fin del trabajo. Esta revitalización de la sociología del trabajo trae consigo la reflexión y atingencia del concepto de precariedad, en una discusión no acabada, pero que aquí instalamos a partir de una propuesta inédita de medición del fenómeno para Chile. En nuestro país, la precariedad se movería transversalmente por la estructura del empleo, a partir de la incidencia multidimensional y compleja en las condiciones de trabajo que aquí abordaremos.

De este modo, ante el escenario de las profundas transformaciones sufridas por el trabajo se vuelve necesario proponer nuevos instrumentos y aproximaciones, por lo que creemos que la precariedad sirve para identificar diferentes formas de debilitamiento e incertidumbre dadas por los cambios en los modelos de gestión empresarial, de pauperización y de control/vigilancia en el trabajo, entre otros factores de carácter estructural. La precariedad puede ser entendida como una relación social y una heterogénea condición de clase que desmonta y problematiza los enfoques tradicionales de entender las características estructurales de composición de las clases sociales a partir del trabajo. En suma, las fisonomías del trabajo han explotado y se han reconfigurado de forma tal que han proliferado diferentes maneras de manifestarse, siendo la precariedad un prisma para la identificación de las diferentes caras y morfologías de las situaciones clasistas, reordenando segmentos, perfiles y obligando a presentar nuevas perspectivas para su estudio y comprensión.

\section{Marco de referencia}

\section{La precariedad laboral de la sociedad}

La precariedad avanza como un fenómeno transversal de degradación de las condiciones de trabajo y de vida, que, sumado a la estructura dual (formal/informal) del mercado laboral, problematiza los viejos espacios de reconocimiento e identificación. Las condiciones de degradación del empleo desplazan los procesos de reconocimiento y malestar (psico)social desde la formalidad hacia la informalidad, desde la estabilidad hacia la inestabilidad y desde la seguridad hacia la inseguridad, como fenómenos transversales de colonización de los mundos de la vida laboral y de los imaginarios del trabajo (Julián, 2017). Estos procesos de precarización no solo cruzan segmentos de trabajadores de baja cualificación, sino que también alcanzan a profesiones tradicionalmente cargadas de mayor estatus y estabilidad. 
A nivel subjetivo, la precariedad laboral se manifiesta en la aparición de fenómenos de individualidad, riesgo, incertidumbre (ausencia de certezas) e inseguridad (Beck, 2000; Castel, 2010). En este conjunto de problematizaciones para el estudio del trabajo, la conformación de una (supuesta) "nueva clase trabajadora" encuentra una contradicción nodal: por una parte, las formas de degradación y fragmentación de los vínculos recién nombradas, que daban forma al núcleo de identidad(es) históricamente asociada(s) al trabajo, y, por otra parte, la gestación de una convergencia y cohesión estructural bajo la condición de precariedad laboral como expresión de una nueva "cuestión social del trabajo".

En el presente artículo se explora una multiplicidad de fisonomías de las precariedades laborales en su aspecto objetivo y se propone una tipología diversa de grupos que nos aproximen a un primer mapeo estadístico que deberá profundizarse cualitativa y geográficamente. La ausencia de subjetividad en nuestra tipología de precariedad refiere sobre todo a la complejidad que implica disponer de todo este conocimiento en un artículo de difusión científica, más que a una propuesta epistemológica neopositivista de la realidad social².

La hipótesis central que guía esta indagación es que la precariedad se mueve fluidamente por la estructura del empleo a partir de una forma multidimensional de incidencia en las condiciones de trabajo, induciendo condiciones de incertidumbre e insuficiencia que se expresan tanto en los nuevos modos de gestión empresarial como en las estrategias individuales y colectivas para enfrentar sus consecuencias $^{3}$. En este escenario, la precariedad introduce una problematización en los enfoques tradicionales del empleo, ya que visibiliza la preocupación por la transversalidad de las formas que asume el trabajo en la geografía del nuevo orden global (en relación con las políticas laborales, la institucionalidad, las clases sociales y las dinámicas económicas del capitalismo contemporáneo).

La precariedad se encontraría asociada a distintas vertientes y dimensiones que, desde la década de 1980, se han convertido en una tendencia a nivel internacional en el reordenamiento de los espacios de trabajo y de restructuración productiva (Auer y Cazes, 2000; Antunes, 2001; Castel y Dörre, 2009; Marín, 2013). Esta incorporación de la precariedad como parte de la nueva realidad del empleo exhibe una aparente permeabilidad e internalización de los debates de las ciencias y estudios del trabajo sobre los cambios en la matriz socioproductiva (Kalleberg, 2011; Paugam y Zhou, 2007; Van der Linden, 2014), un nuevo escenario de flexibilización de las relaciones de empleo (EspingAndersen y Regini, 2000; Thompson y Van den Broek, 2010) y una connotación especial respecto de los procesos constitutivos de resistencias, colectividades y movilización social (Frege y Kelly, 2003; Ross, 2008; Barattini, 2009; De la Garza, 2001). A nivel teórico, la precariedad se ha estudiado desde diversos enfoques, entre los que pueden destacarse tres: i) un enfoque institucionalista y regulacionista, centrado en la protección social y en la definición de la precariedad como producto de un proceso de descomposición del Estado, erosión de las condiciones del empleo y retroceso de las políticas de aseguramiento social (Castel, 2004 y 2010); ii) un enfoque neomarxista, que problematiza la relación y reproducción de la precariedad con los procesos y cambios globales en los patrones de acumulación

\footnotetext{
2 Para nuestro trabajo, enmarcado en el Proyecto FONDECYT Regular núm. 1161347, hemos realizado entrevistas centradas en cuatro niveles de análisis: i) los sentidos y las narrativas del trabajo; ii) el proceso de trabajo; iii) los impactos en las esferas más allá del trabajo, y iv) las asociatividades, la acción colectiva y las estrategias de sobrevivencia. Además, hemos mantenido encuentros de discusión y debate con organizaciones sindicales de diversas ramas y regiones del país sobre las subjetivaciones adscritas a cada tipo de clúster que se exponen en este artículo. Esto representa un trabajo de mayor extensión y es una propuesta de síntesis de un proceso de investigación más amplio y de mayor envergadura que no es posible mostrar aquí.

3 Los cambios en la organización del trabajo, el aumento de la flexibilidad laboral y la incorporación de tecnologías en los espacios productivos han elevado la importancia y las preocupaciones por las calificaciones y competencias requeridas en economías globalizadas, tendencias que han repercutido en los procesos del trabajo y las relaciones laborales (Boltanski y Chiapello, 1999). En Chile, sin embargo, no existe una realización plena en esta directriz, en tanto las trasformaciones de las empresas se han caracterizado por una "modernización desbalanceada" (Ramos, 2009), donde, si bien es cierto que se observan cambios organizacionales de los procesos productivos y de las relaciones laborales, esto no ha repercutido en un cambio profundo en la situación de los trabajadores, quienes se mantienen en posiciones secundarias, débiles y muy subordinadas (Aravena, 2016, págs. 108-111).
} 
de capital, especialmente a través de la financierización, el despojo y la sobreexplotación del trabajo (Dörre, 2009), y iii) un enfoque posestructuralista, que concibe la precariedad como parte de una estrategia y un régimen de gobierno que redefine las formas de control, dominación y subordinación de poblaciones específicas (Butler, 2004; Lorey, 2015).

Se utiliza el concepto de precariedad en vez del concepto de pobreza sobre todo porque este último generalmente ha sido entendido desde la posesión o carencia de recursos (ingresos), invisibilizando su relación con el trabajo y el empleo. En un sentido "multidimensional", la pobreza supone una interconexión práctica en formas de hábitat, salud, educación, ocupación y seguridad social, pero "precariedad" sigue siendo un término más específicamente vinculado a resaltar la centralidad del trabajo. En ese sentido, la precariedad implica una relación con condiciones de pobreza: algunos de los trabajadores precarios son, a la vez, trabajadores pobres. Sin embargo, esta no es la única dimensión de la precariedad, ya que se cruza con situaciones de indefensión y situaciones laborales en que se transgrede la condición de pobreza y se cuestiona la institucionalización de mecanismos de desprotección, expulsión y seguridad social, entendiéndolos como parte indisoluble de las profundas transformaciones de las sociedades capitalistas. De la misma forma, no se usa el concepto de "calidad del empleo", ya que este se circunscribe a una normatividad de condiciones concebidas desde una visión estatista, salarial y restrictiva del trabajo. La precariedad comportaría la carga de las relaciones de poder y de clase que se constituyen en la privación de condiciones de trabajo y de vida, por lo que la "calidad" no se atribuiría de forma automática como imperativo práctico para la subjetivación.

\section{La medición de la precariedad en las clases sociales}

La precariedad es un fenómeno significativamente asociado a las transformaciones del trabajo, que se mueve de manera fluida por la estructura del empleo. En el capitalismo contemporáneo, la división social del trabajo y la explotación requieren de la precarización como una relación instituida para presionar y tensionar las posibilidades de reproducción de la fuerza de trabajo. Su institucionalización en las políticas neoliberales, así como su persistencia estructural en la sociedad chilena, permiten considerarla como una relación social central, instituida y constitutiva de la reproducción social. Ello ha dado forma a manifestaciones heterogéneas del trabajo precario, así como a la formación y composición de las clases sociales existentes.

De este modo, la precariedad tiene directa relación con las nuevas fisonomías del trabajo y de las clases sociales. Ahora bien, los problemas para cuantificarla aparecen en el preciso momento en que nos damos cuenta de lo significativamente problemático que resulta medir clases sociales mediante variables de ocupación o empleo. En principio, clases sociales y ocupaciones se situarían en órdenes teóricos diferentes: las variables de ocupación expresarían la estratificación interna de la división técnica y funcional del trabajo, mientras que las clases sociales se definirían por la posición en las relaciones sociales de poder, lucha y dominación en torno a la producción y distribución del excedente. El problema de cómo medir clases sociales mediante variables de ocupación y empleo es, seguramente, uno de los aspectos más relevantes a la hora de proponer investigaciones estadísticas en torno a las clases sociales y, de forma más precisa, de la precariedad como fenómeno transversal y transclasista.

La principal razón para ello reside en las complejas dimensiones analíticas que se han planteado en los debates en torno a las clases sociales, lo que en ocasiones vuelve difícil o francamente imposible su operacionalización en investigaciones concretas. La polisemia del concepto reúne un amplio número de perspectivas respecto de su significado, y en el área de la sociología se generan profundos debates en torno a la resolución de aspectos ligados a la mutua determinación de dimensiones estructurales y agenciales (Giddens, 1996; Archer, 2009), la articulación de niveles micro- y macrosociales (Wright, 1994; Grusky, Weeden y Sørensen, 2001; Goldthorpe, 2010), la contraposición de alcances ontológicos 
abstractos y concretos (Marx, 1971; Wright, 1994), y los énfasis objetivos y subjetivos (Bourdieu, 1994, 2001, 2002 y 2011). En general, hay un relativo consenso respecto de que los diferentes tópicos de los análisis de clases sociales distinguen entre un análisis preocupado por abordar preguntas relativas a macrofenómenos de transformación o reproducción de las estructuras sociales a gran escala, y un análisis preocupado por explicar fenómenos de nivel micro en las actitudes, los comportamientos o las posibilidades de vida de agentes específicos.

Más aún, algunos enfoques interpretan la crisis de la sociedad salarial keynesiano-fordista como el advenimiento de las sociedades de consumo, donde las prácticas simbólicas e ideológicas en torno a este expresarían, a nivel de la conciencia y la subjetividad, su supremacía como mecanismo identitario y de cohesión social. No obstante, nuestra posición consiste en definir las clases desde las transformaciones ocurridas en el seno del trabajo - o sea, desde los espacios de la producción (donde el trabajo se aplica y pone en práctica) y del mercado laboral (donde el trabajo se vende como una mercancía) - , lo que resulta crucial para nuestro objetivo de explorar la precariedad del trabajo y las clases en una sociedad periférico-dependiente como la nuestra (Blanco, 2016 y 2019). Más allá de la importancia que puede asignarse al consumo como lugar de configuración de desigualdades y configuración identitaria, sostenemos que es en los procesos de producción -es decir, del trabajo como relación social - donde las clases viven situaciones de subordinación, control o supervisión, así como una red de formas contractuales, de acceso a cualificaciones, ingresos, sistemas de seguridad, extensiones de jornadas y demás, que tejen las fisonomías de precariedad multifacéticas y específicas de nuestra sociedad.

Con todo, volvemos al problema inicial: ¿es posible utilizar variables ocupacionales y de empleo para dar cuenta de modelos y relaciones de clases? Al indagar en la bibliografía, notamos que este problema con frecuencia se elude y la discusión sobre cómo se relacionan las ocupaciones con los conceptos de clase social se convierte en un caso de "caja negra" (González y Carabaña, 1992). Algunos autores han señalado que los modelos de clase no se reducen a meras clasificaciones de los mercados laborales (Crompton, 1994), pero no ofrecen soluciones prácticas sobre cómo pasar de un ámbito a otro, ni tampoco sobre de qué forma la ocupación se puede utilizar como variable sustitutiva (proxy) de la clase. Esta ausencia explicativa suele estar presente en la obra de muchos autores que han producido abundantes investigaciones empíricas ${ }^{4}$.

Aquí se propone un diseño de investigación flexible, donde el telón de fondo que justifica el uso de las variables laborales guarda relación con las profundas transformaciones sufridas por el trabajo. A la división funcional en cuanto a las calificaciones se agrega la dimensión de las situaciones del empleo en tanto indicadores de las posiciones en las relaciones de trabajo (Blanco, 2019). De esta forma, una clase social no sería solo un conjunto de grandes agregados de calificaciones, sino también de las posiciones en las relaciones laborales de producción. Las profundas transformaciones históricas del capitalismo proliferaron y multiplicaron las formas del trabajo, creando un amplio abanico de agrupamientos y segmentos, donde las ocupaciones y situaciones de empleo son elementos estructuradores centrales para aproximarnos a estos fragmentos del trabajo.

\footnotetext{
4 Bourdieu, por ejemplo, utiliza categorías ocupacionales tomadas de la clasificación del Institut national de la statistique et des études économiques (INSEE) de Francia y parece no desconfiar en lo más mínimo de esta taxonomía. Asumiendo un pragmatismo rampante, señala que hay que superar la disyuntiva "entre una teoría pura (y dura) de las clases sociales, pero que no se basa en ningún dato empírico (posición en las relaciones de producción, etc.) y que carece de toda eficacia para describir el estado de la estructura social o de sus transformaciones, y trabajos empíricos, como los del INSEE, que no se basan en ninguna teoría, pero que proporcionan los únicos datos disponibles para analizar la división en clases" (Bourdieu, 2003, págs. 54-55). Hay otros investigadores que, lisa y llanamente, liquidaron este paso de operacionalización de variables de ocupación en indicadores de clases y terminaron por proponer mediciones empíricas de las ocupaciones de carácter marcadamente microscópico, reemplazando así las grandes agregaciones de clase (Grusky y Weeden, 2005), excluyendo del análisis de clase todo tipo de agregados sociales amplios y enfilando hacia análisis de clase por la vía de las ocupaciones específicas al nivel más desagregado posible (Grusky y Sørensen, 1998). En estos dos ejemplos se puede decir que los investigadores toman los indicadores de los que disponen sin mayores ejercicios de operacionalización teórico-metodológica de sus variables.
} 


\section{Metodología}

\section{Variables utilizadas: los cinco componentes de la precariedad}

Los cambios del capitalismo se relacionan con nuevos paradigmas productivos - en cuanto a cambios en el proceso del trabajo y a la (re)organización del trabajo en la empresa (Ramos, 2009) la flexibilización del empleo (Echeverría y López, 2004) y el surgimiento de trabajos atípicos (De la Garza, 2000 y 2001; Neffa, 2010). Esto da forma a nuevas condiciones de producción y constitución de experiencias productivas, así como del proceso de organización de los sentidos en el trabajo (Antunes, 2005). Las dinámicas de los modelos productivos y la transformación de las formas de gestión racional del trabajo, así como las transformaciones que responden a la crisis de la hegemonía del modelo industrial-keynesiano-fordista, tuvieron un profundo impacto en las dimensiones contractuales y organizacionales (Gálvez, 2001; Palomino, 2001).

De esta manera, en esta investigación la precariedad se entiende en cinco dimensiones específicas: i) estabilidad (contractual y temporal), ii) seguridad (protección social), iii) suficiencia (ingresos), iv) condiciones de trabajo (accidentabilidad por ocupación y caracterización de los lugares de trabajo) y v) cronopiedad ${ }^{5}$ (véase el cuadro 1).

Cuadro 1

Operacionalización multidimensional de la precariedad laboral

\begin{tabular}{|c|c|c|}
\hline Componente & Definición operativa & Indicador casen 2013 \\
\hline \multirow[t]{4}{*}{ (In)estabilidad } & \multirow[t]{4}{*}{$\begin{array}{l}\text { Ausencia de contrato, existencia de contratos } \\
\text { temporales, de corta duración, de incierta finalización. }\end{array}$} & $\begin{array}{l}\text { - ¿Su trabajo o negocio principal } \\
\text { es de tipo ...? }\end{array}$ \\
\hline & & - Tipo de contrato. \\
\hline & & - Contrato de trabajo escrito. \\
\hline & & $\begin{array}{l}\text { - ¿Con quién firmó su contrato o } \\
\text { estableció su acuerdo de trabajo? }\end{array}$ \\
\hline \multirow[t]{3}{*}{ (In)seguridad } & \multirow{3}{*}{$\begin{array}{l}\text { Este componente se refiere a la ausencia (o no) } \\
\text { de cobertura en salud y previsión social. }\end{array}$} & - Afiliado al sistema previsional. \\
\hline & & - Cotiza en algún sistema previsional. \\
\hline & & - Sistema previsional (salud). \\
\hline \multirow[t]{2}{*}{ (In)suficiencia } & \multirow{2}{*}{$\begin{array}{l}\text { Este componente hace mención de la } \\
\text { cantidad del salario/ingreso. }\end{array}$} & - Ingreso del trabajo (agrupado) \\
\hline & & - Ingreso ocupación principal (agrupado) \\
\hline \multirow[t]{2}{*}{ Condiciones de trabajo } & \multirow[t]{2}{*}{$\begin{array}{l}\text { Dimensión que considera la accidentabilidad por } \\
\text { ocupación y la caracterización de los lugares de trabajo. }\end{array}$} & $\begin{array}{l}\text { - Lugar en donde realiza la actividad } \\
\text { o se ubica el negocio. }\end{array}$ \\
\hline & & - Enfermedad o accidente. \\
\hline Cronopiedad & $\begin{array}{l}\text { Este componente se basa en la cantidad de horas } \\
\text { de trabajo que se realiza semanalmente. }\end{array}$ & $\begin{array}{l}\text { - Horas de trabajo empleo } \\
\text { principal (agrupado). }\end{array}$ \\
\hline
\end{tabular}

Fuente: Elaboración propia.

La problematización metodológica de la precariedad laboral ha tenido diferentes expresiones, experiencias e instrumentos en lo que respecta a su medición en América Latina, aportes con los que se vuelve necesario dialogar y profundizar un modelo de análisis integral (Escoto, 2010; Grau y Lexartza, 2010; Rubio, 2010; Monteforte, 2012; Mora, 2010; Fernández, 2014; Guadamarra,

\footnotetext{
5 Por "cronopiedad" hacemos alusión tanto a fenómenos de subempleo (actividades que de forma significativa no alcanzan las 45 horas semanales) como a aquellas situaciones donde se sobrepasan de forma relevante dicho estándar de la jornada laboral semanal.
} 
Hualde y López, 2015)6. De ahí que nuestra propuesta de análisis trabaje con cinco componentes centrales de la precariedad laboral, dimensiones extraídas de un proceso de revisión de las propuestas metodológicas de medición de la precariedad laboral en diversos contextos de América Latina. Considerando las propuestas realizadas por Mora (2010) -icónicas en cuanto a indicadores de precariedad de empleo-, se integran estos cinco niveles de problematización de la precariedad en el empleo asalariado. La fuente de los datos fue la encuesta de Caracterización Socioeconómica Nacional 2013 (CASEN 2013), que contiene todas las variables contempladas en esta operacionalización (lo que no se encontró en la encuesta CASEN 2015) 7.

\section{Variables utilizadas: clases, ocupaciones y situaciones de empleo}

Otras dos variables que resultan significativas son la Clasificación Internacional Uniforme de Ocupaciones (CIUO-1988) y la Clasificación Internacional de la Situación en el Empleo (CISE), ambas elaboradas y trabajadas durante décadas por la Organización Internacional del Trabajo (OIT). En el marco de referencia se define el término "clase social" no solo como un conjunto de agregados de calificaciones, sino también de las posiciones en las relaciones laborales de producción. Esto se traduce en dos dimensiones centrales del concepto: clases como situaciones de empleo y clases como ocupaciones (Blanco, 2019).

La situación del empleo -operacionalizada por la CISErec (véase el cuadro 2) - involucra el trabajo en tanto relación social, es decir, una diversidad de formas de sujeción directa e indirecta, abordando las porosas fronteras entre el trabajo asalariado y dependiente, el trabajo por cuenta propia y otras formas de relaciones laborales atípicas, expresando las transformaciones en las relaciones contractuales y en las formas de organización/explotación que surgieron en las últimas décadas (Gálvez, 2001; Palomino, 2001). Por su parte, la ocupación - que fue operacionalizada por medio de la variable CIUOrec (véase el cuadro 3) - expresa la división funcional de los oficios y las profesiones, diferenciando distintos grados de calificación (manual, no manual, de servicios y comercio, profesionales calificados, técnicos de nivel medio, empleados de oficina, trabajos agrícolas, no calificados y otros). Ambas variables han sido recodificadas: en el caso de la CISErec se eliminó a patrones o empleadores, mientras que en el caso de la ClUOrec se crearon nuevos grupos, tales como directores/gerentes de empresas, miembros del Poder Ejecutivo y cuerpos legislativos y administración pública, agricultores y trabajadores agropecuarios y pesqueros de subsistencia, entre otros.

Cuadro 2

Clasificación Internacional de la Situación en el Empleo (CISE) y su recodificación (CISErec)

\begin{tabular}{lll}
\hline CISE & CISErec & Abreviación \\
\hline Trabajador por cuenta propia & Trabajador por cuenta propia & Trab cuent prop \\
\hline Empleado u obrero del sector público (gobierno central y municipalidades) & Empleado u obrero del sector público & Emp SPúb \\
\hline Empleado u obrero del sector público (empresas públicas) & & \\
\hline Empleado u obrero del sector privado & Empleado u obrero del sector privado & Emp SPriv \\
\hline Servicio doméstico puertas adentro & Servicio doméstico puertas adentro & ss dom paf \\
\hline Servicio doméstico puertas afuera & Servicio doméstico puertas afuera & ss dom pad \\
\hline Familiar no remunerado & Familiar no remunerado & Fam no rem \\
\hline
\end{tabular}

Fuente: Elaboración propia.

6 No obstante, es imposible plantear en tan poco espacio una discusión sobre las formas de medición de la precariedad, considerando que las posibilidades de detallar específicamente cada uno de los modelos de medición citados involucran un riguroso trabajo analítico que rebasa los objetivos de este artículo. Faltaría realizar un artículo completo que tenga por objeto complementar la propuesta aquí esbozada, detallando cada uno de los modelos desplegados en la medición de precariedad laboral y del trabajo en América Latina.

7 En la encuesta CASEN 2015 desaparece la importante variable o26, lo que nos llevó a elegir la versión de 2013 a fin de tener la mayor cantidad de indicadores para todas las dimensiones de precariedad aquí propuestas. 
Cuadro 3

Clasificación Internacional Uniforme de Ocupaciones (CIUO) y su recodificación (CIUOrec)

\begin{tabular}{|c|c|c|}
\hline CIUO & CIUOrec & Abreviación \\
\hline \multirow{4}{*}{$\begin{array}{l}\text { Miembros del poder ejecutivo y de los } \\
\text { cuerpos legislativos y personal directivo de } \\
\text { la administración pública y de empresas }\end{array}$} & $\begin{array}{l}\text { Miembros del poder ejecutivo y de los cuerpos legislativos } \\
\text { y personal directivo de la administración pública }\end{array}$ & Ejec Legisl Adm Púb \\
\hline & Jefes de pequeñas poblaciones & Jefes peq pob \\
\hline & Directores de organizaciones especiales & Dir Org Esp \\
\hline & Directores o gerentes de empresas & Dir Gerent \\
\hline Profesionales científicos e intelectuales & Profesionales científicos e intelectuales & Prof cientif int \\
\hline Técnicos y profesionales de nivel medio & Técnicos y profesionales de nivel medio & Téc prof nivel M \\
\hline Personal de apoyo administrativo & Personal de apoyo administrativo & Apoyo adm \\
\hline $\begin{array}{l}\text { Trabajadores de los servicios y } \\
\text { vendedores de comercios y mercados }\end{array}$ & $\begin{array}{l}\text { Trabajadores de los servicios y vendedores } \\
\text { de comercios y mercados }\end{array}$ & Trab ss vend com merc \\
\hline \multirow[t]{2}{*}{$\begin{array}{l}\text { Agricultores y trabajadores calificados } \\
\text { agropecuarios, forestales y pesqueros }\end{array}$} & $\begin{array}{l}\text { Agricultores y trabajadores calificados o semicalificados } \\
\text { agropecuarios, forestales y pesqueros }\end{array}$ & Agric calif sem calif \\
\hline & $\begin{array}{l}\text { Agricultores y trabajadores agropecuarios } \\
\text { y pesqueros de subsistencia }\end{array}$ & Agric pesq subs \\
\hline $\begin{array}{l}\text { Oficiales, operarios y artesanos de } \\
\text { artes mecánicas y de otros oficios }\end{array}$ & $\begin{array}{l}\text { Oficiales, operarios y artesanos de artes mecánicas } \\
\text { y de otros oficios }\end{array}$ & Of op art mec ofi \\
\hline $\begin{array}{l}\text { Operadores de instalaciones y } \\
\text { máquinas y ensambladores }\end{array}$ & Operadores de instalaciones y máquinas y ensambladores & Op inst maq \\
\hline Ocupaciones elementales & Trabajadores no calificados & Trab no calif \\
\hline
\end{tabular}

Fuente: Elaboración propia.

Para la caracterización de los clústeres se han usado variables tales como rama económica, región y sexo. También se ha creado una variable - denominada "fracción de clase" - que combina las modalidades de la ocupación (CISErec) y de la situación del empleo (CISErec), con lo que se llegó a un total de 78 categorías (13×6) (véase el cuadro 4). Ello responde a que ninguna clase social es por sí misma una alineación social internamente homogénea: en su interior existen significativas diferencias y variabilidades que dan cuenta de "desigualdades intracategoriales" (Fitoussi y Rosanvallon, 1997, págs. 73-81). Con esto se demostrará que en cada clúster de precariedad se observa un amplio y fragmentado abanico de agrupamientos y segmentos, donde los contextos laborales se resquebrajan y agrietan las formas clásicas del trabajo, afectando directamente la fisonomía de las clases.

Cuadro 4

La variable "fracción de clase"

\begin{tabular}{lcccccc}
\hline \multirow{2}{*}{ ClUOrec } & \multicolumn{7}{c}{ CISErec } \\
\cline { 2 - 7 } & $\begin{array}{c}\text { 1. Trab } \\
\text { cuent prop }\end{array}$ & 2. Emp SPúb & 3. Emp SPriv & 4. ss dom pad & 5. ss dom paf & 6. Fam no rem \\
\hline 1. Trab no calif & 1,1 & 1,2 & 1,3 & 1,4 & 1,5 & 1,6 \\
\hline 2. Op inst maq & 2,1 & 2,2 & 2,3 & 2,4 & 2,5 & 2,6 \\
\hline 3. Of op art mec ofi & 3,1 & 3,2 & 3,3 & 3,4 & 3,5 & 3,6 \\
\hline 4. Agric pesq subs & 4,1 & 4,2 & 4,3 & 4,4 & 4,5 & 4,6 \\
\hline 5. Agric calif sem calif & 5,1 & 5,2 & 5,3 & 5,4 & 5,5 & 5,6 \\
\hline 6. Trab ss vend com merc & 6,1 & 6,2 & 6,3 & 6,4 & 6,5 & 6,6 \\
\hline 7. Apoyo adm & 7,1 & 7,2 & 7,3 & 7,4 & 7,5 & 7,6 \\
\hline 8. Téc prof nivel M & 8,1 & 8,2 & 8,3 & 8,4 & 9,5 & 9,6 \\
\hline 9. Prof cientif int & 9,1 & 9,2 & 9,3 & 9,4 & 10,5 & 10,6 \\
\hline 10. Dir Gerent & 10,1 & 10,2 & 10,3 & 10,4 & 11,5 & 11,6 \\
\hline 11. Dir Org Esp & 11,1 & 11,2 & 11,3 & 11,4 & 12,5 & 12,6 \\
\hline 12. Jefes_peq_pob & 12,1 & 12,2 & 12,3 & 12,4 & 13,5 & 13,6 \\
\hline 13. Ejec Legisl Adm Púb & 13,1 & 13,2 & 13,3 & 13,4 & 14,5 & 14,6 \\
\hline
\end{tabular}

Fuente: Elaboración propia. 


\section{Técnicas estadísticas}

En el tratamiento de los datos se combina una técnica de análisis factorial para datos categóricos (análisis de correspondencias múltiples o ACM) con el análisis de clúster de k-medias. La técnica del ACM estudia la relación entre variables y categorías de las variables nominales $u$ ordinales, al tiempo que reduce la variabilidad conjunta a factores/dimensiones que las resumen (Escofier y Pagès, 1992; Ferrán, 2001; Visauta y Martori, 2003; Pérez, 2004; Le Roux y Rouanet, 2010). Se obtienen gráficos que expresan visualmente estas relaciones y resultan de especial relevancia las relaciones de cercanía y distancia: las categorías relacionadas se encuentran más cercanas que aquellas que no están relacionadas y que están más lejos.

La segunda técnica utilizada fue un análisis de conglomerado con modelo no jerárquico de k-medias que hace posible encontrar patrones de agrupamiento, lo que, a su vez, permite descubrir la manera en que los individuos se aglomeran o diferencian entre sí (Ferrán, 2001; Visauta y Martori, 2003; Pérez, 2004). El análisis de clúster estima las similitudes entre los individuos u objetos a través de la correlación (distancia o asociación) de las diferentes variables. Posteriormente, se establece un procedimiento que permite comparar los grupos en virtud de las similitudes, donde el investigador puede decidir cuántos grupos se construyen, tratando de formar el mínimo número de grupos, lo más homogéneos posibles dentro de sí y lo más heterogéneos posibles entre sí.

Los pasos para poder generar la tipología de precariedad se resumen de la siguiente manera:

- En un primer momento, las variables del cuadro 1, más las recodificaciones de la CISE (cuadro 2) y de la ClUO-88 (cuadro 3) se incorporan a un análisis de correspondencias múltiples (ACM). Con este procedimiento obtenemos los dos continuos que sintetizan la información de todas las variables incluidas en el modelo.

- Estos dos factores que resumen la información multivariada son guardados en la base de datos como dos nuevas variables métricas referidas a las coordenadas de los casos. Estas dos nuevas variables métricas se utilizan en un análisis de clúster de k-medias, estableciéndose los conglomerados (clústeres). No fueron, entonces, ni las variables de precariedad ni las de ocupación y situación de empleo las que se introdujeron al análisis de conglomerados, sino que única y exclusivamente se ingresaron los puntajes de los objetos/casos a lo largo de ambas dimensiones. De esta manera, se evitó incluir variables no métricas (nominales u ordinales) en el método de k-medias, que está diseñado para utilizarse con variables continuas.

- Se analizan diferentes posibilidades de disminución de la varianza interna de los grupos mediante ANOVA de una vía, proceso mediante el cual se define el número final de perfiles ${ }^{8}$.

- El paso siguiente es la caracterización de los grupos por medio de una serie de variables laborales, socioeconómicas y demográficas. Se incorporan tanto las variables de la operacionalización de la precariedad, las recodificaciones de CISE y CIUO-88, así como otras variables de caracterización socioeconómica y demográfica. Por medio de esto se puso un nombre a cada clúster según las características de precariedad y de clases más relevantes.

\footnotetext{
8 Los análisis de varianza indican un 9,1\% de heterogeneidad interna de los nueve grupos respecto de los puntajes factoriales en el eje 1 y un 11,9\% respecto de los puntajes en el eje 2 . Es decir, un 90,9\% de los puntajes factoriales del eje 1 se explican por la tipología de nueve grupos, mientras que un $88,1 \%$ de las puntuaciones factoriales de los puntos del eje 2 se explican por la diferencia entre los nueve grupos de la tipología de precariedad.
} 


\section{Resultados}

\section{El modelo multidimensional de la precariedad laboral}

El modelo factorial del análisis de correspondencia múltiple realizado con las variables de precariedad y de clases sociales conforma dos dimensiones, con un coeficiente Alfa de Cronbach de 0,873 para el primer factor y de 0,746 para el segundo. En cuanto a la inercia, en total el modelo de dos factores explica un 64,3\%: el primer factor alcanza un 39,6\% y el segundo un 24,7\% (véanse los cuadros 5 y 6 ).

Cuadro 5

Resumen del modelo

\begin{tabular}{|c|c|c|c|}
\hline \multirow{2}{*}{ Dimensión } & \multirow{2}{*}{ Alfa de Cronbach } & \multicolumn{2}{|c|}{ Varianza contabilizada para } \\
\hline & & Total (autovalor) & Inercia \\
\hline 1 & 0,873 & 5,149 & 0,396 \\
\hline 2 & 0,746 & 3,211 & 0,247 \\
\hline Total & & 8,36 & 0,643 \\
\hline Media & $0,824^{a}$ & 4,18 & 0,322 \\
\hline
\end{tabular}

Fuente: Elaboración propia, sobre la base de la Encuesta de Caracterización Socioeconómica Nacional (CASEN) 2013.

a La media de alfa de Cronbach se basa en la media de autovalor.

Cuadro 6

Medidas discriminantes

\begin{tabular}{llll}
\hline & \multicolumn{2}{c}{ Dimensión } & Media \\
\cline { 2 - 3 } & 1 & 2 & 0,246 \\
\hline 012. ¿Su trabajo o negocio principal es de tipo...? & 0,349 & 0,144 & 0,138 \\
\hline 016. Tipo de contrato & 0,156 & 0,119 & 0,158 \\
\hline 017. Contrato de trabajo escrito & 0,263 & 0,053 & 0,06 \\
\hline 020. ¿Con quién firmó su contrato o estableció su acuerdo de trabajo? & 0,071 & 0,049 & 0,365 \\
\hline 026. Lugar en donde realiza la actividad o se ubica el negocio & 0,527 & 0,203 & 0,213 \\
\hline 029. Afiliado a sistema previsional & 0,409 & 0,018 & 0,223 \\
\hline 030. Cotiza en algún sistema previsional & 0,385 & 0,061 & 0,471 \\
\hline s14. Sistema previsional & 0,538 & 0,405 & 0,01 \\
\hline s17. Enfermedad o accidente & 0,015 & 0,005 & 0,165 \\
\hline 010. Horas de trabajo, empleo principal (agrupado) & 0,251 & 0,079 & 0,702 \\
\hline Ingreso ocupación principal (agrupado) & 0,682 & 0,722 & 0,7 \\
\hline Ingreso del trabajo (agrupado) & 0,692 & 0,709 \\
\hline Fracción de clase & 0,813 & 0,644 & 0,729 \\
\hline Clúster ${ }^{\text {a }}$ & 1,132 & 0,981 & 1,056 \\
\hline Total activo & 5,149 & 3,211 & 4,18 \\
\hline
\end{tabular}

Fuente: Elaboración propia, sobre la base de la Encuesta de Caracterización Socioeconómica Nacional (CASEN) 2013.

a Variable suplementaria. 
Gráfico 1

Perfiles de precariedad laboral en el espacio multidimensional

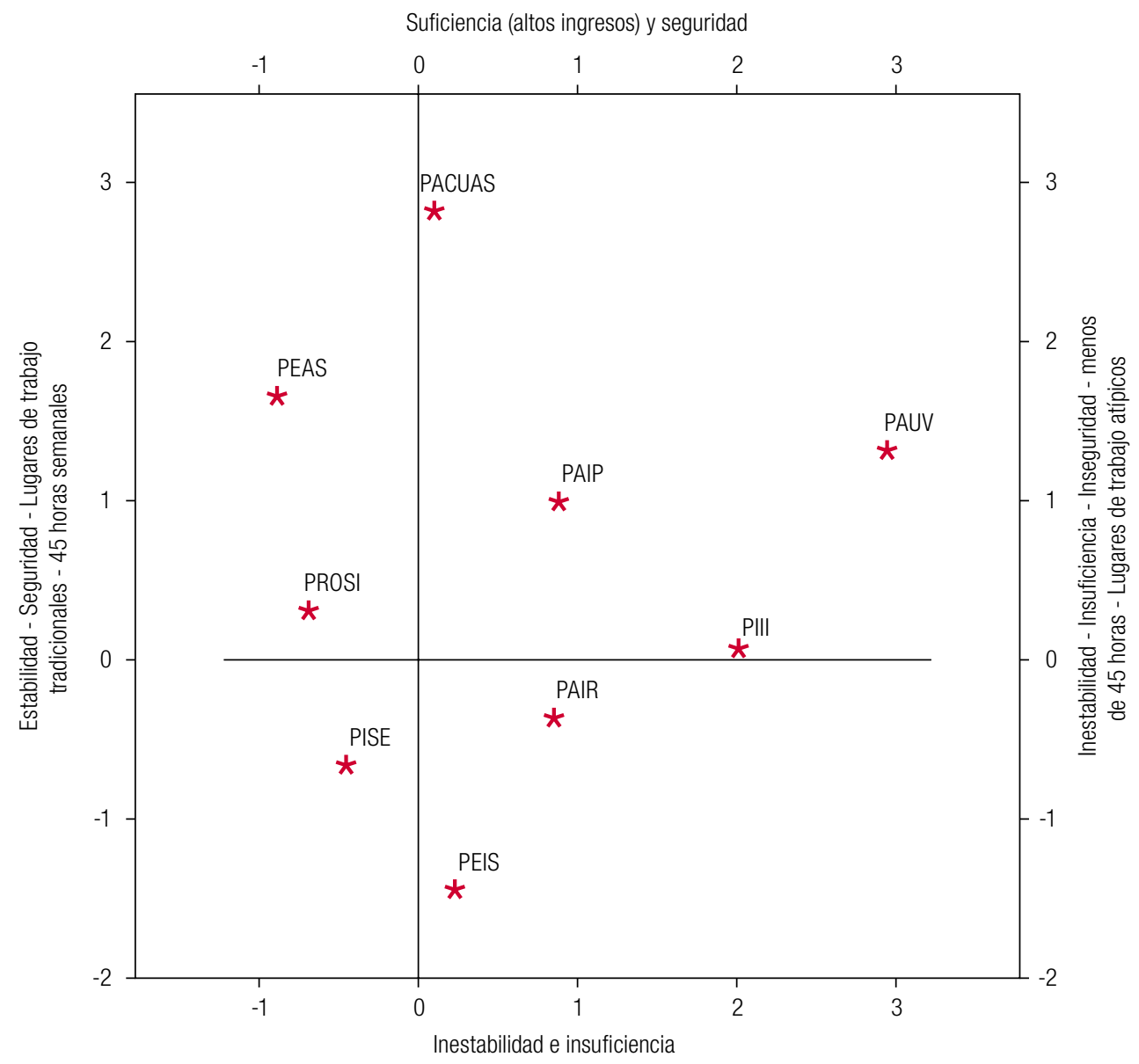

Fuente: Elaboración propia, sobre la base de la Encuesta de Caracterización Socioeconómica Nacional (CASEN) 2013.

Nota: Precarios de Autonomía y Cualificación Superior (PACUAS); Protegidos Estables de Aseguramiento Superior (PEAS); Precarios de Alta Intensidad Permanente (PAIP); Precarios Autónomos de Vulnerabilidad Sistémica (PAUV); Precarios Informales Inestables en Insuficiencia (PIII); Precarios Estacionales de Insuficiencia Salarial (PEIS); Precarios de Insuficiencia Segura y Estable (PISE) y Precarios de alta inseguridad y estabilidad relativa (PAIR).

\section{Primera dimensión/eje 1}

Al analizar las categorías con mayores contribuciones de inercia explicada por esta dimensión, es posible señalar que mientras los puntajes negativos remiten a situaciones de protección laboral, los puntajes positivos nos hablan de situaciones de precarización (véanse los cuadros 7 y 8 y los gráficos 1 y 16). Los puntajes negativos están ligados a estabilidad (contratos firmados, trabajos de plazos indefinidos y negociaciones directas con la empresa), seguridad (afiliación del trabajador dependiente al sistema previsional/las administradoras de fondos de pensiones (AFP)), condiciones de trabajo (ligadas a lugares de trabajo tradicionales: fábricas, oficinas y sitios afines) y cronopiedad (jornadas de 45 horas semanales) (véase el cuadro 7). No existen categorías de clases sociales con contribuciones significativas a la inercia y puntajes factoriales positivos. No obstante, al incorporar los clústeres como variables complementarias se observa que uno de los conglomerados más protegidos del mercado laboral chileno - Protegidos Estables de Aseguramiento Superior (PEAS) - posee tanto importantes contribuciones en esta primera dimensión como puntajes factoriales negativos. 
Cuadro 7

Categorías con puntajes factoriales negativos y mayor contribución (primera dimensión/eje 1)

\begin{tabular}{|c|c|c|c|c|}
\hline Categoría & Variable & $\begin{array}{l}\text { Dimensión de } \\
\text { precariedad }\end{array}$ & $\begin{array}{l}\text { Contribución de } \\
\text { la dimensión a la } \\
\text { inercia del punto } \\
\text { (en porcentajes) }\end{array}$ & $\begin{array}{l}\text { Coordenadas } \\
\text { factoriales }\end{array}$ \\
\hline Sí, firmó & 0.17 & (In)estabilidad & 56 & 0,509 \\
\hline $\begin{array}{l}\text { Sí, AFP. Cotización obligatoria } \\
\text { del trabajador dependiente }\end{array}$ & 0.30 & (In)seguridad & 50 & 0,492 \\
\hline Plazo indefinido & 0.16 & (In)estabilidad & 37 & 0,493 \\
\hline $\begin{array}{l}\text { Directamente con la empresa } \\
\text { o negocio donde trabaja }\end{array}$ & 0.20 & (In)estabilidad & 27 & 0,307 \\
\hline $\begin{array}{l}\text { En un establecimiento independiente } \\
\text { (fábrica, oficina, etc.) }\end{array}$ & 0.26 & $\begin{array}{l}\text { Condiciones } \\
\text { de Trabajo }\end{array}$ & 22 & 0,407 \\
\hline Sí, está afiliado a sistema previsional & 0.29 & (In)seguridad & 15 & 0,157 \\
\hline 45 horas & 0.10 & Cronopiedad & 11 & 0,394 \\
\hline PEAS ${ }^{a}$ & Clúster & - & 10 & 0,882 \\
\hline
\end{tabular}

Fuente: Elaboración propia, sobre la base de la Encuesta de Caracterización Socioeconómica Nacional (CASEN) 2013.

a Categoría de variable complementaria.

Cuadro 8

Categorías con puntajes factoriales positivos y mayor contribución (primera dimensión/eje 1)

\begin{tabular}{|c|c|c|c|c|}
\hline Categoría & Variable & $\begin{array}{l}\text { Dimensión de } \\
\text { precariedad }\end{array}$ & $\begin{array}{l}\text { Contribución de } \\
\text { la dimensión a la } \\
\text { inercia del punto } \\
\text { (en porcentajes) }\end{array}$ & $\begin{array}{l}\text { Coordenadas } \\
\text { factoriales }\end{array}$ \\
\hline Decil I & Ingreso Ocupación Principal & (In)suficiencia & 42 & $-2,226$ \\
\hline S. Público FONASA Grupo A & s.14 & (In)seguridad & 37 & $-1,43$ \\
\hline PAUVa & Clúster & - & 33 & $-2,944$ \\
\hline No afiliado a sistema previsional & 0.29 & (In)seguridad & 32,5 & $-1,729$ \\
\hline Decil I & Ingreso del Trabajo & (In)suficiencia & 32 & $-2,451$ \\
\hline Ocasional o eventual & 0.12 & (In)estabilidad & 23 & $-1,986$ \\
\hline$<=44$ horas & 0.10 & Cronopiedad & 23 & $-0,735$ \\
\hline$P\|\|^{a}$ & Clúster & - & 23 & $-2,011$ \\
\hline No está cotizando & 0.30 & (In)seguridad & 21 & $-1,203$ \\
\hline Decil ॥ & Ingreso del Trabajo & (In)suficiencia & 17 & $-1,389$ \\
\hline Of op art mec ofi \& Trab cuent prop ${ }^{b}$ & Fracción de clase & - & 12 & $-1,885$ \\
\hline Trab no calif \& Trab cuent prop ${ }^{c}$ & Fracción de clase & - & 12 & $-2,412$ \\
\hline A domicilio (casa del empleador o cliente) & 0.26 & $\begin{array}{l}\text { Condiciones } \\
\text { de Trabajo }\end{array}$ & 12 & $-1,201$ \\
\hline Dentro de su vivienda & 0.26 & $\begin{array}{l}\text { Condiciones } \\
\text { de Trabajo }\end{array}$ & 11 & $-1,892$ \\
\hline
\end{tabular}

Fuente: Elaboración propia, sobre la base de la Encuesta de Caracterización Socioeconómica Nacional (CASEN) 2013.

a Categoría de variable complementaria.

b Oficiales y operarios de artes mecánicas y otros oficios por cuenta propia.

c Trabajadores no calificados por cuenta propia.

Por su parte, los puntajes positivos de esta primera dimensión (véase el cuadro 8) indican mayores contribuciones a la inercia debido a situaciones de inestabilidad (empleos ocasionales o eventuales), insuficiencia (deciles de bajos ingresos), inseguridad (Grupo A del sistema público de salud FONASA, no afiliados al sistema previsional o, en el caso de estar afiliados, no cotización), condiciones de trabajo (ligadas a la realización de actividades en lugares no tradicionales, tales 
como domicilios de clientes o viviendas propias) y cronopiedad (vinculada a jornadas de menos de 44 horas semanales) (véase el cuadro 8). Los puntajes positivos de esta primera dimensión poseen, además, una significativa relación con ocupaciones manuales por cuenta propia y trabajos no calificados también por cuenta propia. Considerados como variables complementarias, los clústeres más relacionados con esta zona del plano factorial son los de Precarios Informales Inestables en Insuficiencia (PIII) y Precarios Autónomos de Vulnerabilidad Sistémica (PAUV), dos grupos con un alto grado de vulnerabilidad e informalidad.

\section{Segunda dimensión/eje 2}

Las categorías con mayores contribuciones a la inercia explicada por esta segunda dimensión indican puntajes negativos ligados a situaciones de precariedad, mientras que los puntajes positivos se encuentran relacionados a condiciones de protección (véanse los cuadros 8 y 9 y los gráficos 1 y 16). De este modo, en el lado de los puntajes negativos de este segundo factor tenemos dimensiones de precariedad vinculadas a la inestabilidad (con trabajos a plazo fijo) y la insuficiencia (deciles III de ingresos del trabajo y de la ocupación principal) (véase el cuadro 8). La fracción de clase de los trabajadores no calificados dependientes en el sector privado muestra una importante relación con los puntajes negativos de esta segunda dimensión, misma situación de los conglomerados Precarios Estacionales de Insuficiencia Salarial (PEIS) y Precarios de Insuficiencia Segura y Estable (PISE). En ese sentido, estamos hablando de un sector del plano factorial caracterizado por situaciones de precariedad con condición de dependencia, con o sin contratos de trabajos firmados, de baja o nula cualificación e ingresos.

\section{Cuadro 9}

Categorías con puntajes factoriales negativos y mayor contribución (segunda dimensión/eje 2)

\begin{tabular}{|c|c|c|c|c|}
\hline Categoría & Variable & $\begin{array}{l}\text { Dimensión de } \\
\text { precariedad }\end{array}$ & $\begin{array}{c}\text { Contribución de } \\
\text { la dimensión a la } \\
\text { inercia del punto } \\
\text { (en porcentajes) }\end{array}$ & $\begin{array}{l}\text { Coordenadas } \\
\text { factoriales }\end{array}$ \\
\hline PEIS ${ }^{\mathrm{a}}$ & Clúster & - & 22 & 1,456 \\
\hline PISE $^{a}$ & Clúster & - & 20 & 0,659 \\
\hline Decil III & Ingreso Ocupación principal & (In)suficiencia & 17 & 0,908 \\
\hline Plazo fijo & 0.12 & (In)estabilidad & 14,5 & 0,775 \\
\hline Trab no calif \& Emp SPriv ${ }^{b}$ & Fracción de clase & - & 14 & 1,009 \\
\hline Decil III & Ingreso del trabajo & (In)suficiencia & 13 & 0,878 \\
\hline
\end{tabular}

Fuente: Elaboración propia, sobre la base de la Encuesta de Caracterización Socioeconómica Nacional (CASEN) 2013.

a Categoría de variable complementaria.

b Trabajadores no calificados dependientes en el sector privado.

En los puntajes positivos de este segundo factor se encuentran condiciones ligadas a la suficiencia (deciles $X$ de ingresos del trabajo y de la ocupación principal) y la seguridad (Institución de Salud Previsional, ISAPRE) (véase el cuadro 10). La fracción de clase vinculada a este sector del espacio factorial es la de los profesionales, científicos e intelectuales dependientes en el sector privado, mientras que los clústeres más representativos son los de Precarios de Autonomía y Cualificación Superior (PACUAS) y Protegidos Estables de Aseguramiento Superior (PEAS). De este modo, esta zona del plano factorial se caracterizaría por condiciones cercanas a la alta calificación, con situaciones de empleo en condiciones variables, que irían desde la autonomía (cuenta propia) hasta la dependencia protegida (asalariada). 
Cuadro 10

Categorías con puntajes factoriales positivos y mayor contribución (segunda dimensión/eje 2)

\begin{tabular}{llccc}
\hline Categoría & Variable & $\begin{array}{c}\text { Dimensión de } \\
\text { precariedad }\end{array}$ & $\begin{array}{c}\text { Contribución de } \\
\text { la dimensión a la } \\
\text { inercia del punto } \\
\text { (en porcentajes) }\end{array}$ & $\begin{array}{c}\text { Coordenadas } \\
\text { factoriales }\end{array}$ \\
\hline DecilX & Ingreso del trabajo & (In)suficiencia & 37 & $-1,871$ \\
\hline DecilX & Ingreso ocupación principal & (In)suficiencia & 36 & $-1,991$ \\
\hline PEAS & Clúster & - & 36 & $-1,645$ \\
\hline ISAPRE $^{\text {a }}$ & S.14 & (In)seguridad & 33 & $-1,275$ \\
\hline Prof cient int \& Emp SPriv & bracción de clase & - & 13 & $-1,351$ \\
\hline PACUAS $^{\text {b }}$ & Clúster & - & 11 & $-2,81$ \\
\hline
\end{tabular}

Fuente: Elaboración propia, sobre la base de la Encuesta de Caracterización Socioeconómica Nacional (CASEN) 2013.

a Categoría de variable complementaria.

b Profesionales, científicos e intelectuales dependientes en el sector privado.

\section{Los nueve tipos de precariedad laboral en Chile: características principales}

Los resultados del tratamiento conjunto de los datos con ACM y clúster de k-medias permitieron elaborar nueve conglomerados que clasifican distintos tipos de situaciones frente a la precariedad. A continuación, se presenta una descripción y caracterización de los grupos identificados en la tipología, detallando sus principales rasgos en relación con la precariedad, la composición por sexo, la distribución geográfica, la rama económica, los deciles de ingresos y la adecuación a las categorías ocupacionales.

Cuadro 11

Chile: los nueve clústeres de precariedad laboral

\begin{tabular}{|c|c|c|c|}
\hline Nombre & & Porcentaje & Características fundamentales \\
\hline PEAS & $\begin{array}{l}\text { Protegidos estables de } \\
\text { aseguramiento superior }\end{array}$ & $\begin{array}{l}12 \% \\
N=876645\end{array}$ & $\begin{array}{l}\text { Grupo caracterizado principalmente por actividades de alta calificación en situación } \\
\text { de dependencia en el sector privado y público. Actividades con seguridades en las } \\
\text { dimensiones de estabilidad, protección, suficiencia y condiciones laborales. La única } \\
\text { dimensión de precariedad significativa es la de la cronopiedad, principalmente por } \\
\text { jornadas mayores a las } 45 \text { horas semanales. }\end{array}$ \\
\hline PROSI & $\begin{array}{l}\text { Protegidos de suficiencia } \\
\text { intermedia }\end{array}$ & $\begin{array}{l}17.4 \% \\
N=1263558\end{array}$ & $\begin{array}{l}\text { Actividades de alta y baja calificación, manuales y no manuales, en situación de } \\
\text { dependencia en el sector privado y, en menor medida, en el público. La precariedad } \\
\text { se observa de forma intermedia en las dimensiones de los ingresos (suficiencia) } \\
\text { y cronopiedad. }\end{array}$ \\
\hline PACUAS & $\begin{array}{l}\text { Precarios de autonomía } \\
\text { y cualificación superior }\end{array}$ & $\begin{array}{l}1,8 \% \\
N=134118\end{array}$ & $\begin{array}{l}\text { Actividades de calificación alta y media en situación de trabajo por cuenta propia. } \\
\text { Altos ingresos, pero se observa precariedad en las dimensiones de estabilidad, } \\
\text { seguridad, condiciones de empleo y cronopiedad (esto último, principalmente por } \\
\text { situación de subempleo). }\end{array}$ \\
\hline PAUV & $\begin{array}{l}\text { Precarios autónomos de } \\
\text { vulnerabilidad sistémica }\end{array}$ & $\begin{array}{l}5,3 \% \\
N=383109\end{array}$ & $\begin{array}{l}\text { Actividades de calificación media y baja en situación de trabajo por cuenta propia. } \\
\text { Se observa precariedad en las dimensiones de estabilidad, seguridad, suficiencia } \\
\text { y condiciones de trabajo. }\end{array}$ \\
\hline PAIP & $\begin{array}{l}\text { Precarios de alta } \\
\text { intensidad permanente }\end{array}$ & $\begin{array}{l}4,9 \% \\
N=359923\end{array}$ & $\begin{array}{l}\text { Actividades de calificación media en situación de trabajo por cuenta propia. La } \\
\text { precariedad se muestra en las dimensiones de seguridad, suficiencia (intermedia), } \\
\text { condiciones de trabajo y cronopiedad (esto último debido a una carga excesiva de } \\
\text { horas semanales). }\end{array}$ \\
\hline PIII & $\begin{array}{l}\text { Precarios informales } \\
\text { inestables en insuficiencia }\end{array}$ & $\begin{array}{l}7,8 \% \\
N=568907\end{array}$ & $\begin{array}{l}\text { Actividades de calificación baja y nula en situación de trabajo por cuenta propia, } \\
\text { con fracciones de actividades de servicios domésticos. Se observa precariedad } \\
\text { en las dimensiones de estabilidad, seguridad, suficiencia, condiciones de trabajo } \\
\text { y cronopiedad. }\end{array}$ \\
\hline PISE & $\begin{array}{l}\text { Precarios de insuficiencia } \\
\text { segura y estable }\end{array}$ & $\begin{array}{l}30,9 \% \\
N=2250517\end{array}$ & $\begin{array}{l}\text { Dependientes en sector privado de actividades de baja y nula calificación. Bajos } \\
\text { ingresos, vale decir, su precariedad se concentra en la dimensión de la suficiencia. }\end{array}$ \\
\hline PEIS & $\begin{array}{l}\text { Precarios estacionales de } \\
\text { insuficiencia salarial. }\end{array}$ & $\begin{array}{l}9.5 \% \\
N=693361\end{array}$ & $\begin{array}{l}\text { Actividades principalmente de nula y baja calificación en situación de dependencia } \\
\text { en sector privado. Las dimensiones de precariedad significativas en este grupo son } \\
\text { la estabilidad, seguridad, suficiencia y condiciones de trabajo. }\end{array}$ \\
\hline PAIR & $\begin{array}{l}\text { Precarios de alta } \\
\text { inseguridad y } \\
\text { estabilidad relativa }\end{array}$ & $\begin{array}{l}10,3 \% \\
N=747,621\end{array}$ & $\begin{array}{l}\text { Grupo principalmente compuesto por actividades de baja y nula calificación en } \\
\text { situación de dependencia en el sector privado combinadas con situaciones de trabajo } \\
\text { por cuenta propia. Las dimensiones de precariedad principales son la estabilidad, } \\
\text { seguridad, suficiencia y condiciones de trabajo. }\end{array}$ \\
\hline
\end{tabular}

Fuente: Elaboración propia. 


\section{Gráfico 2}

Clústeres laborales de precariedad multidimensional

(En porcentajes y frecuencias absolutas ponderadas)

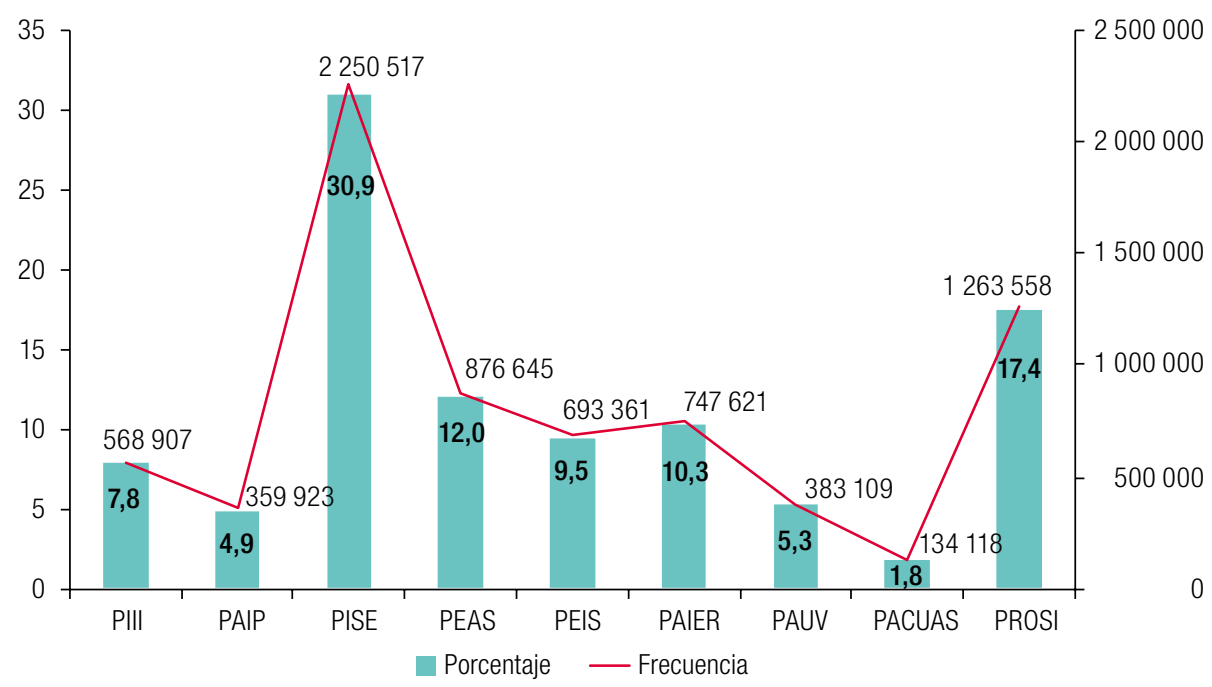

Fuente: Elaboración propia, sobre la base de la Encuesta de Caracterización Socioeconómica Nacional (CASEN) 2013.

\section{Gráfico 3}

Clústeres de precariedad según sexo

(En porcentajes)

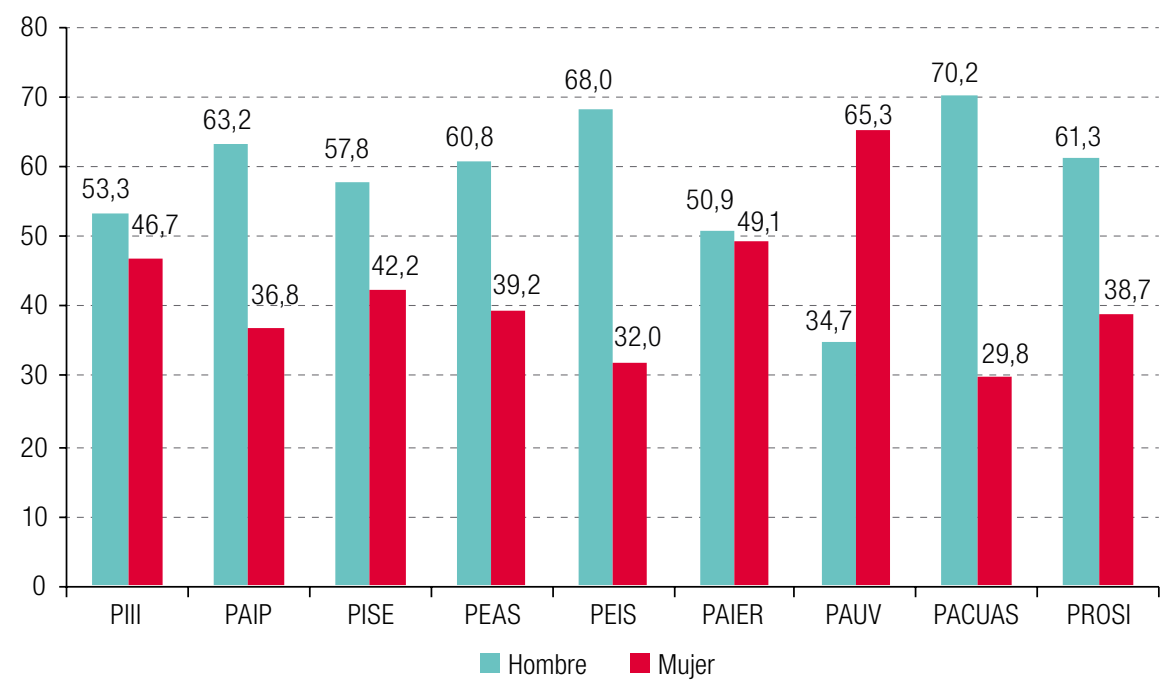

Fuente: Elaboración propia, sobre la base de la Encuesta de Caracterización Socioeconómica Nacional (CASEN) 2013. 


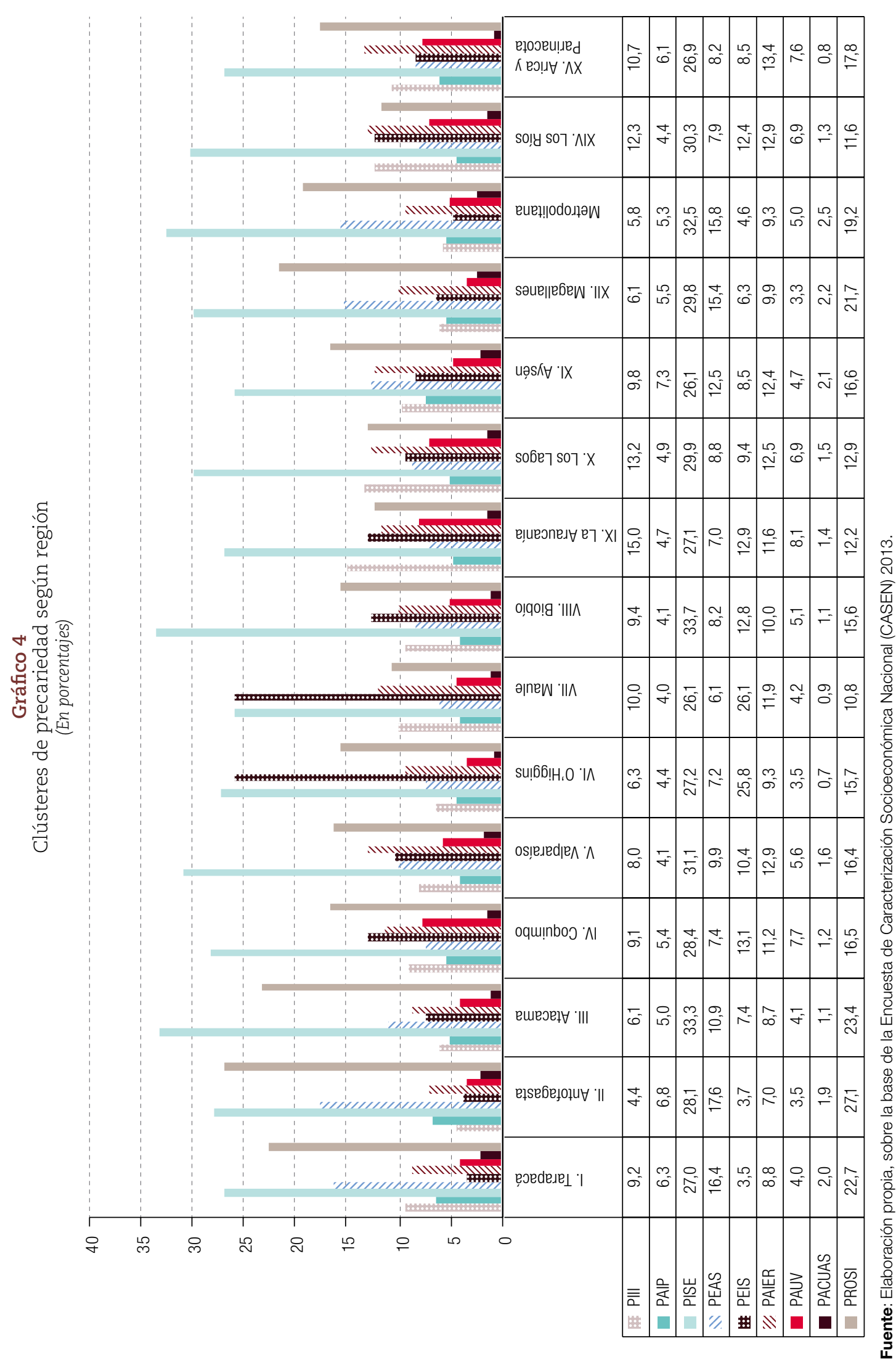




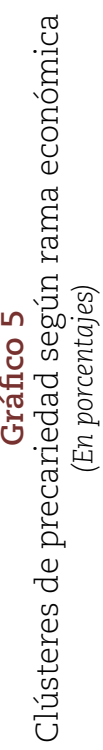

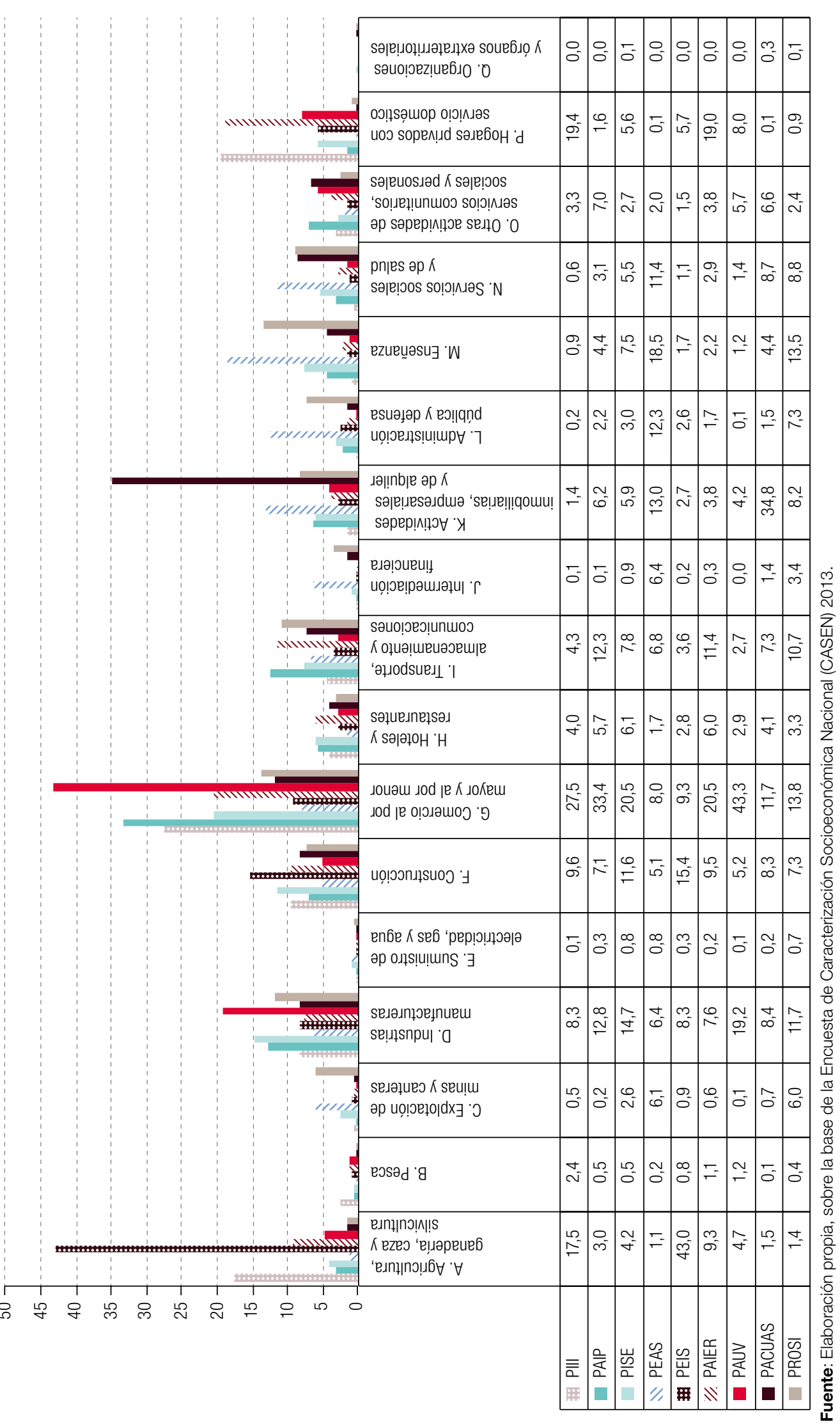




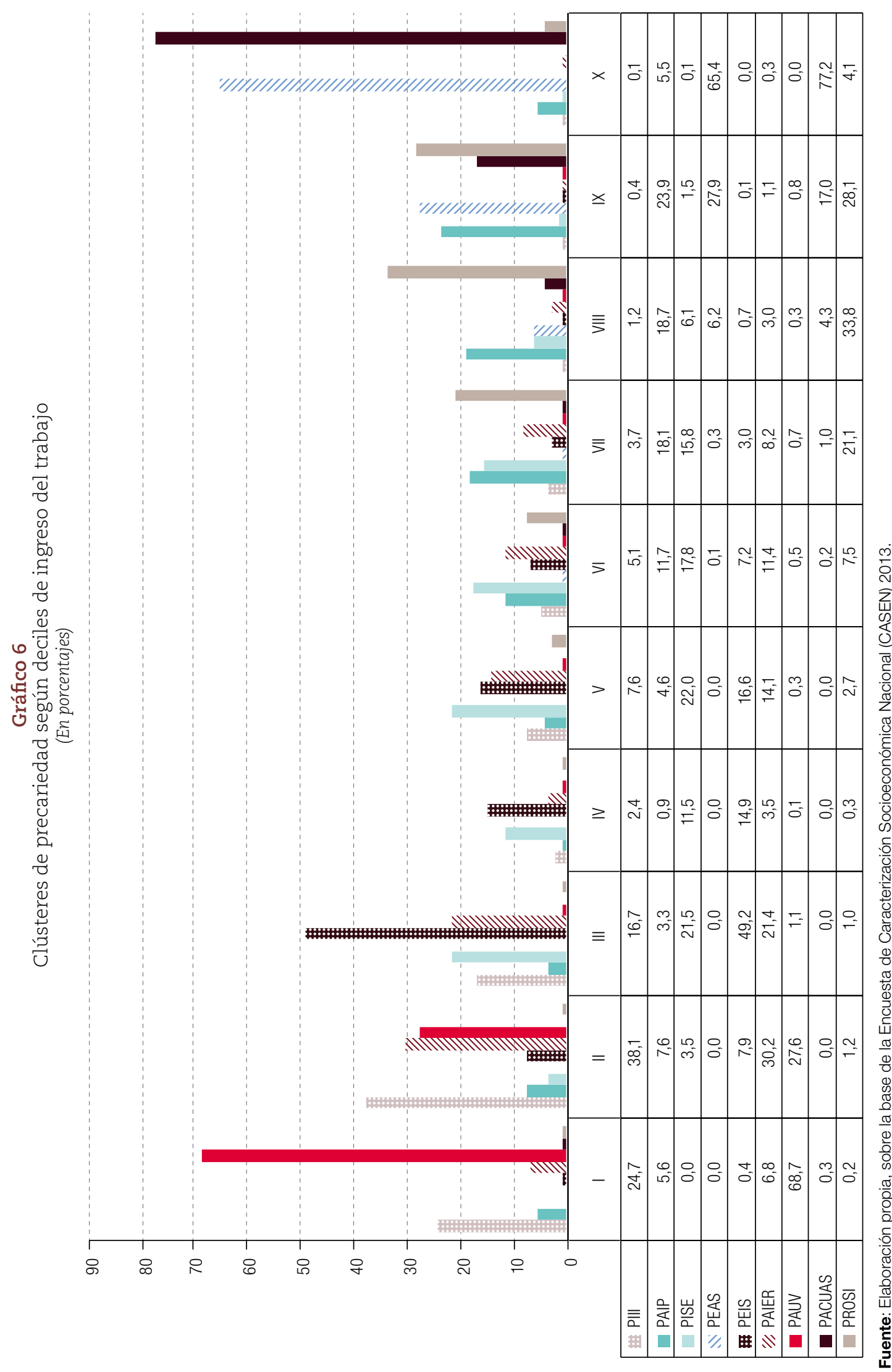




\section{a) Protegidos Estables de Aseguramiento Superior (PEAS)}

Este grupo, que alcanza un 12\% del total de casos del mercado laboral chileno (véase el gráfico 2), se encuentra formado por trabajadores que se ajustan a las jornadas legales, con relaciones de asalarización y subordinación dependiente. Son actividades de tipo permanente que se acompañan de condiciones estables de empleo y contrato, sin presencia de intermediación ni tercerización. Se presentan tanto en el sector público como en el privado y se destaca la alta cualificación de sus ocupaciones. La afiliación a un sistema previsional es casi total, mientras que el sistema de salud que predomina es la ISAPRE. Los ingresos de este grupo se encuentran en los dos deciles más altos, con una media poblacional que iría de 1.383.812 pesos a 1.389.449 pesos (estimación con un 95\% de confianza) (véase el cuadro A1.9). Pese a ser el conglomerado más protegido de toda la tipología, su precariedad estaría relacionada con la dimensión de la cronopiedad, es decir, con una cantidad de horas trabajadas a la semana que superaría el promedio de 45 horas (véase el cuadro A1.12).

La composición de clase del clúster de Protegidos Estables de Aseguramiento Superior se divide fundamentalmente en dos tipos de profesionales, científicos e intelectuales bajo modalidades de dependencia salariada: los que son dependientes en el sector privado (41\%) y los que son dependientes en el sector público (20\%). También se encuentran fracciones de técnicos profesionales de nivel medio dependientes en el sector privado (13\%) y de directores o gerentes de empresas en el sector privado (7\%) (véase el gráfico 7). Los sectores económicos de este conglomerado masculinizado (un $61 \%$ de sus integrantes son hombres) se concentran en los rubros de enseñanza (18,5\%), actividades inmobiliarias, empresariales y de alquiler (13\%), administración pública y defensa (12\%) y servicios sociales y de salud (11\%). Las regiones donde más se observa este tipo de clúster son Tarapacá, Antofagasta, Metropolitana, Magallanes, Aysén, Atacama y Valparaíso.

\section{Gráfico 7}

Fracciones de clase en clúster PEAS ( $\mathrm{N}=876.645)$

(En porcentajes)

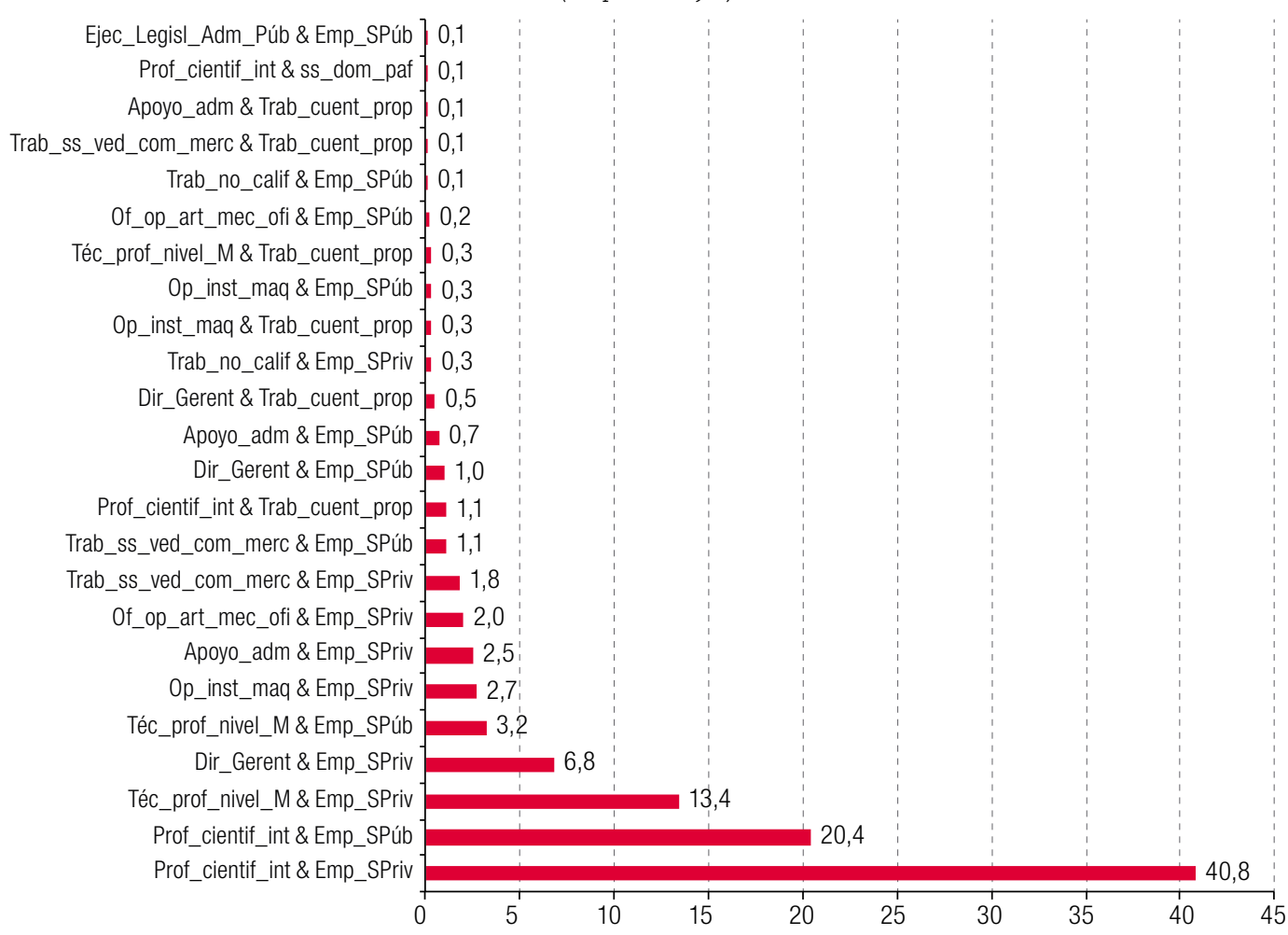

Fuente: Elaboración propia, sobre la base de la Encuesta de Caracterización Socioeconómica Nacional (CASEN) 2013. 


\section{b) Protegidos de Suficiencia Intermedia (PROSI)}

Este importante grupo, que alcanza el 17\% del mercado laboral (véase el gráfico 2), se caracteriza por estar compuesto por trabajadores dependientes en el sector privado, manuales y no manuales, con calificación baja, media y alta (véase el gráfico 8). Se observa una alta protección en materia de salud y una elevada afiliación al sistema previsional. A la vez, comparten una alta estabilidad laboral, con un elevado grado de formalización de los contratos de trabajo y dependencia salarial. En cuanto a la suficiencia de ingresos, este grupo no alcanza significativamente el último decil y por ello goza de una suficiencia intermedia, que puede asociarse a la heterogeneidad de cualificaciones y ocupaciones presentes en él. Así es como sus integrantes se encuentran repartidos entre los deciles VII (32,7\%), VIII (25,9\%) y IX (23\%).

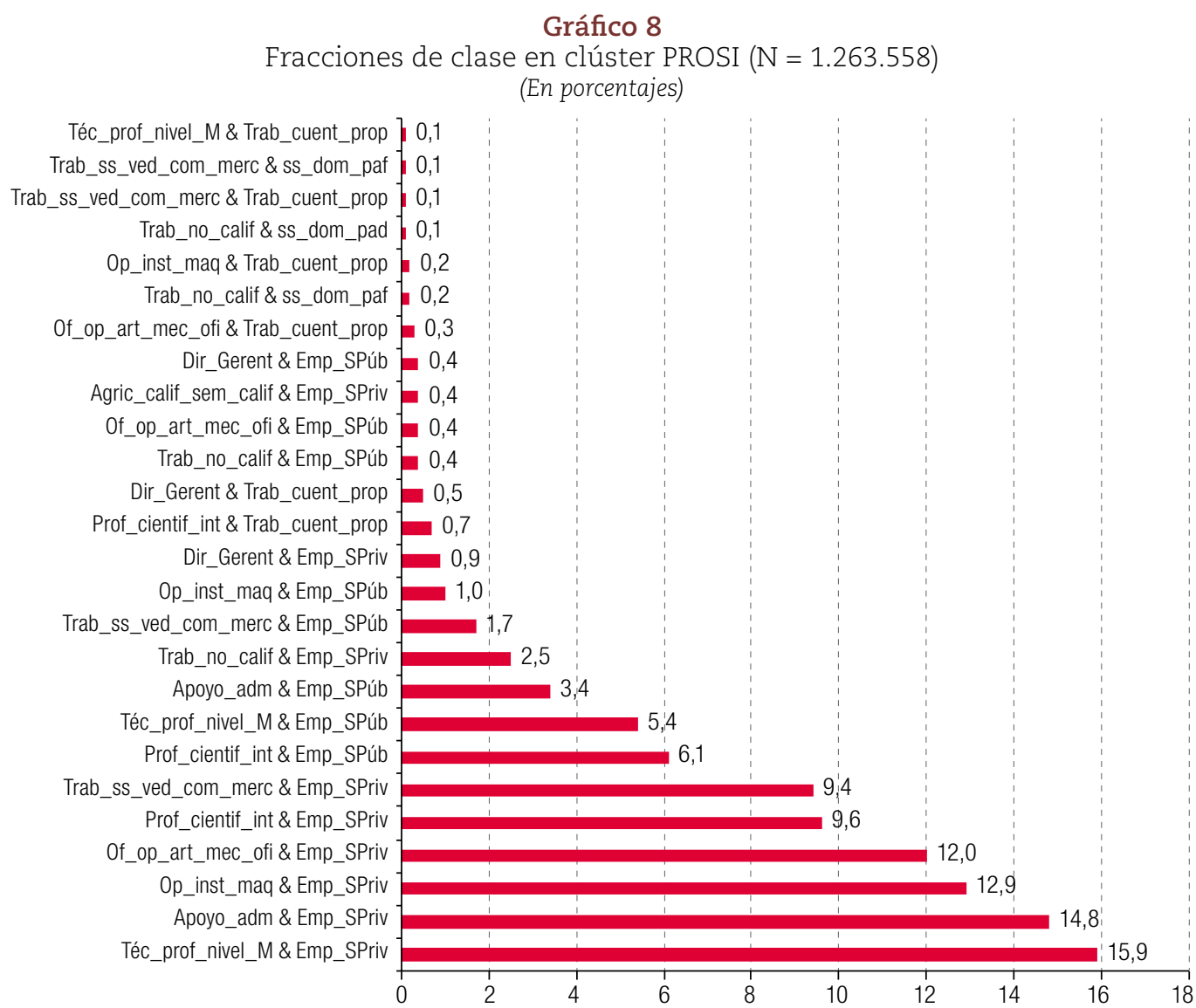

Fuente: Elaboración propia, sobre la base de la Encuesta de Caracterización Socioeconómica Nacional (CASEN) 2013.

Aquellas fracciones de clase que poseen una condición de dependencia en el sector privado son: técnicos, profesionales de nivel medio dependientes (16\%), personal de apoyo administrativo dependiente (15\%), operarios e instaladores de maquinaria dependientes (13\%), oficiales, operarios de artes mecánicas y otros oficios dependientes (12\%), profesionales, científicos e intelectuales (10\%), y trabajadores de servicio y vendedores de comercio y mercados dependientes (9\%). También se encuentran fracciones ligadas al sector público, tales como profesionales, científicos e intelectuales dependientes (6\%), técnicos, profesionales de nivel medio dependientes (5\%), y personal de apoyo administrativo (3\%). 


\section{c) Precarios de Autonomía y Cualificación Superior (PACUAS)}

Este grupo, que apenas alcanza un 1,8\% del total del mercado laboral chileno (véase el gráfico 2), se caracteriza por realizar actividades por cuenta propia, con ocupaciones no manuales y de calificación alta y media. Sus jornadas son de baja intensidad y de carácter flexible. Aunque existe una fracción que señala tener un contrato de trabajo, la característica central del grupo es el trabajo por cuenta propia, mientras que los asalariados cuentan con una mayoría de contratos indefinidos.

La localización del lugar de trabajo exhibe una flexibilidad, lo que puede estar asociado a profesionales que trabajan desde su hogar y en establecimientos donde predomina el trabajo de tipo freelance. Es un grupo con altos ingresos por trabajo principal: un $74 \%$ se concentra en el último decil de ingresos del trabajo, lo que se asocia al hecho de que una significativa proporción prefiera las instituciones de salud privada y se encuentre afiliado a alguna de ellas. No obstante, a nivel previsional existe un segmento que no está afiliado, sumado a una cuarta parte que sí lo está y no cotiza efectivamente. Hay una proporción de casos que muestra los riesgos de esta condición; existe un $25 \%$ de posibilidades de entrar en un subgrupo de mayor exposición a riesgos y precariedad.

Las fracciones de clase más significativas de los Precarios de Autonomía y Cualificación Superior son todas por cuenta propia: profesionales, científicos e intelectuales (47,5\%), técnicos y profesionales de nivel medio (19\%) y directores o gerentes de empresas (12\%) (véase gráfico 9). Además, se trata de un grupo muy masculinizado (70\%) que tiene mayor presencia en las regiones Metropolitana y Magallanes y que desempeña sus actividades principalmente en las ramas de actividades inmobiliarias, empresariales y de alquiler (35\%) y comercio (12\%).

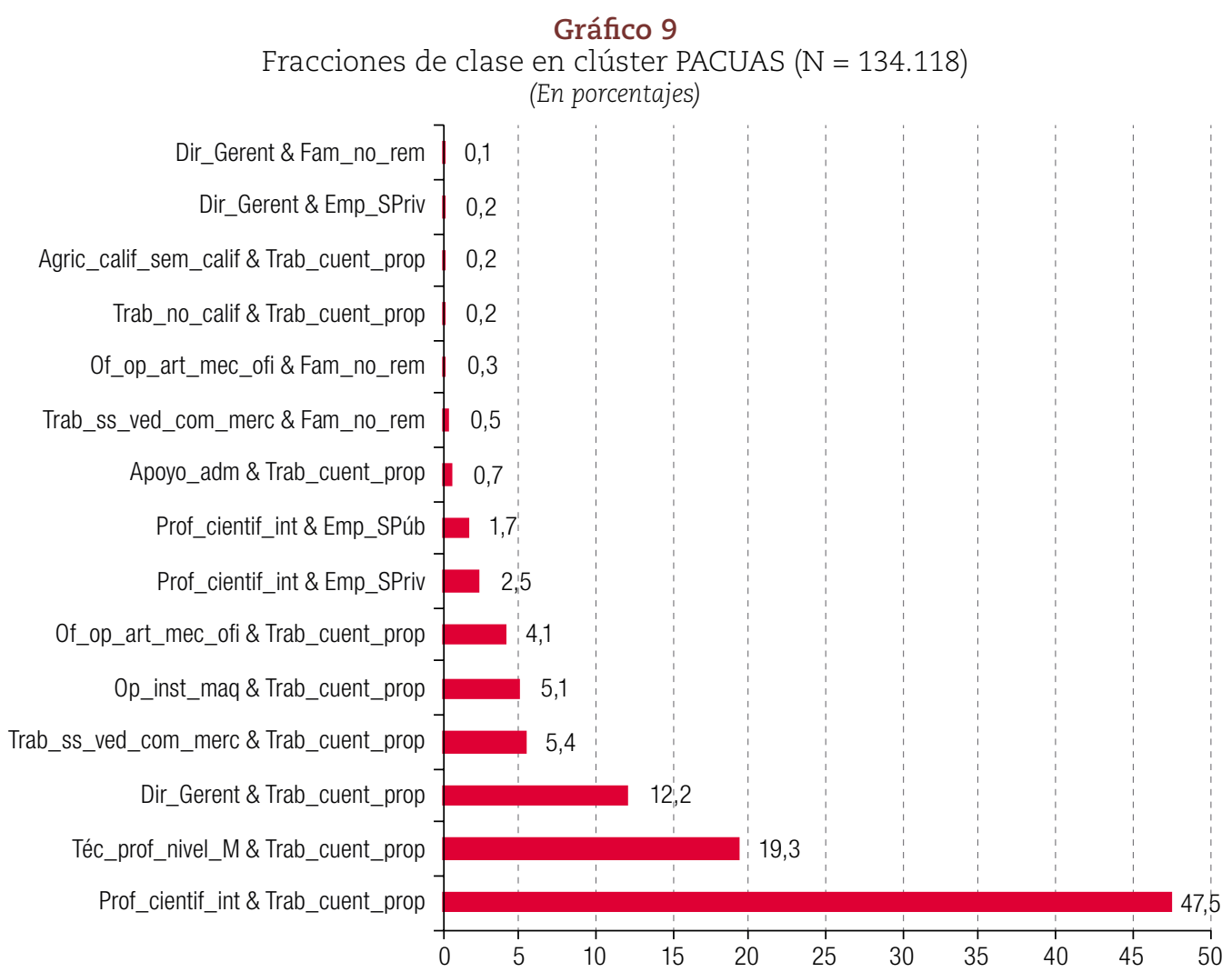

Fuente: Elaboración propia, sobre la base de la Encuesta de Caracterización Socioeconómica Nacional (CASEN) 2013. 


\section{d) Precarios Informales Inestables en Insuficiencia (PIII)}

Este conglomerado, que alcanza un 7,8\% del total (véase el gráfico 2), está compuesto fundamentalmente por trabajadores que poseen un alto grado de informalidad, ya que no cotizan en el sistema previsional, no cuentan con un contrato de trabajo y se amparan en el Grupo A de FONASA. Su intensidad horaria baja y flexible se relaciona con la alta inestabilidad de sus negocios y actividades productivas. La relación de cuenta propia se combina con asalariados de escasa formalización y sin calificación, lo que va acompañado de bajos ingresos. En ese sentido, se caracterizan por una red de fragilidades en materia de protección, seguridad y solvencia.

En el gráfico 10 se puede observar que la composición de clase del grupo de Precarios Informales Inestables en Insuficiencia está dada fundamentalmente por las siguientes categorías: oficiales y operarios de artes mecánicas y otros oficios por cuenta propia (18\%), trabajadores no calificados por cuenta propia (14\%), trabajadores en servicios y vendedores en comercio y mercados por cuenta propia (13\%), servicios domésticos puertas afuera no calificados (11\%), agricultores calificados o semicalificados por cuenta propia (10\%) y trabajadores no calificados dependientes en el sector privado (8\%). Además, este clúster no muestra una diferencia significativa en cuanto al sexo; incluye tanto hombres como mujeres. La Araucanía, Los Lagos y Los Ríos son las regiones que evidencian mayor presencia de este tipo de precariedad, mientras que las ramas del comercio, los hogares con servicio doméstico y la agricultura son los sectores económicos de mayor relevancia.

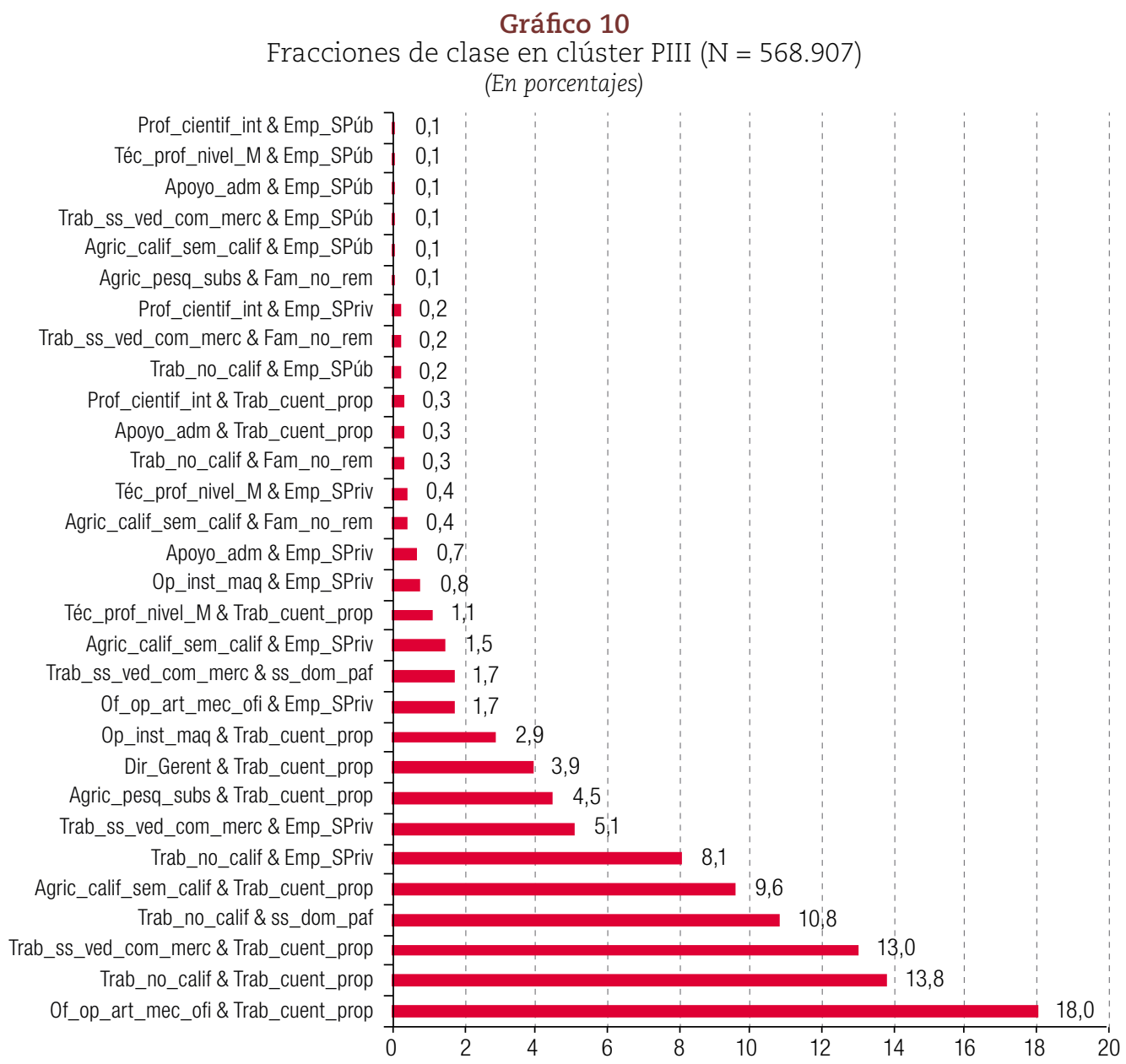

Fuente: Elaboración propia, sobre la base de la Encuesta de Caracterización Socioeconómica Nacional (CASEN) 2013. 


\section{e) Precarios de Alta Intensidad Permanente (PAIP)}

Este grupo alcanza el 4,9\% del total (véase el gráfico 2), con jornadas que exceden los marcos legales, lo que va acompañado de locaciones del trabajo ubicadas en sectores aledaños a la vivienda o la vía pública que dificultan la distinción entre la vida familiar y laboral. Los negocios son de tipo permanente, pese a que la mayoría de quienes poseen contrato se encuentran en el plazo fijo. Los niveles de ingresos son dispares, lo que se ve reflejado en las coberturas de salud. Existe una escisión entre la afiliación a un sistema previsional y la práctica de cotización efectiva, lo que está relacionado con el carácter de cuenta propia y su inestabilidad laboral. La permanencia proviene de esta condición estructural de la temporalidad intensiva de las jornadas, sumada a las dispares condiciones de valorización de la fuerza de trabajo.

Las fracciones de clase más relevantes dentro de este conglomerado se encuentran en situación de trabajo independiente. Entre los principales se cuentan los trabajadores de servicios y vendedores de comercio y mercados por cuenta propia (16\%), los operadores e instaladores de maquinaria por cuenta propia (12\%), y los técnicos y profesionales de nivel medio por cuenta propia (9\%) (véase el gráfico 11). Aunque con cifras significativamente más bajas, también es posible encontrar algunos casos de dependencia en el sector público y privado, con niveles bajos y altos de calificación y ocupaciones de tipo manual y no manual. En cuanto a las ramas económicas, entre los principales se destacan los sectores de comercio (33\%), industria (13\%) y transporte, almacenamiento y comunicaciones (12\%). Además, se observa una mayoría significativa de hombres (63\%), mientras que Aysén y Antofagasta son las regiones más importantes.

\section{Gráfico 11}

Fracciones de clase en clúster PAIP ( $\mathrm{N}=359.923)$

(En porcentajes)

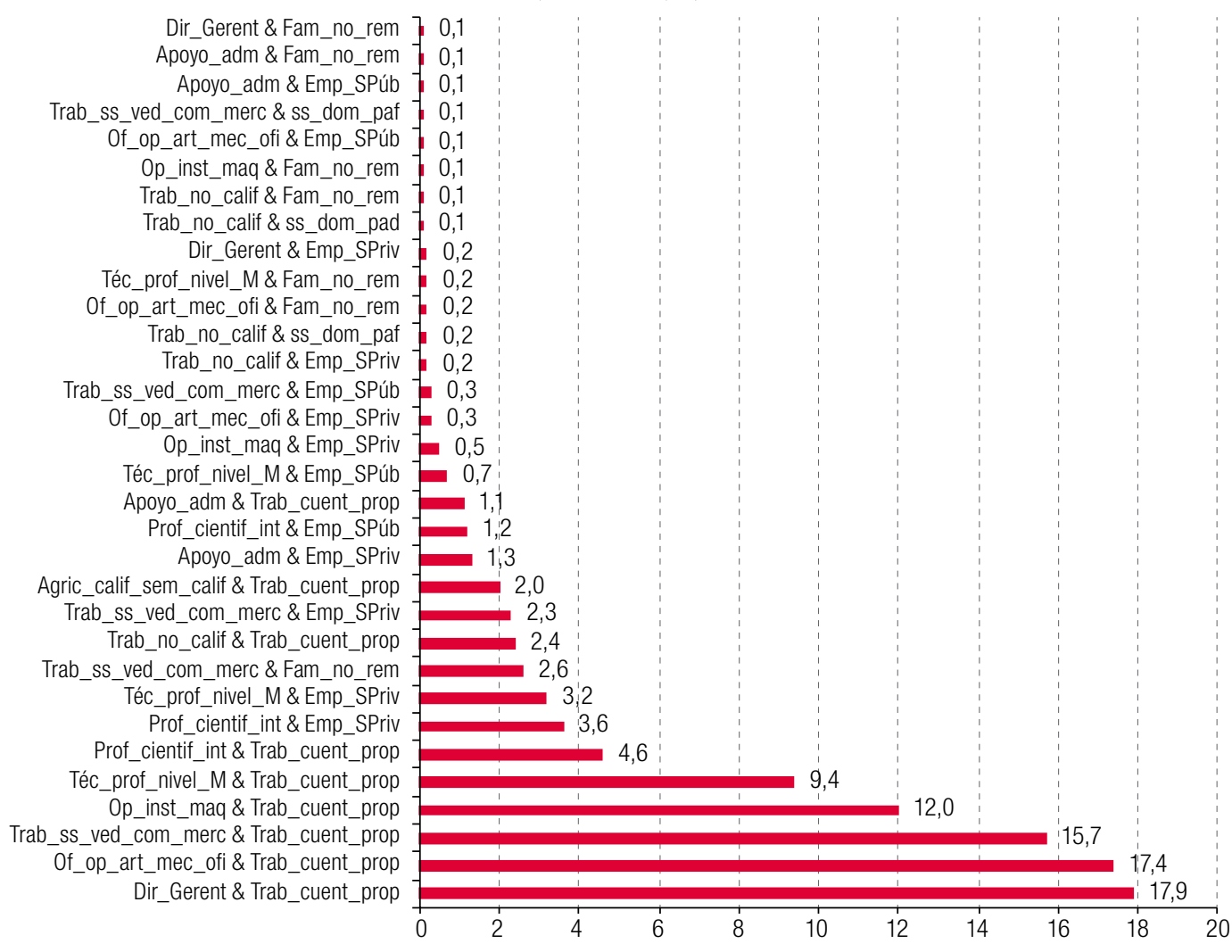

Fuente: Elaboración propia, sobre la base de la Encuesta de Caracterización Socioeconómica Nacional (CASEN) 2013. 


\section{f) Precarios de Insuficiencia Segura y Estable (PISE)}

Este es el grupo con mayor cantidad de casos de toda la tipología (31\%) (véase el gráfico 2); se compone de un conjunto de trabajadores con una dependencia y subordinación salarial muy fuerte. Esta dependencia y el nivel de formalización de los contratos les aseguran una participación en las redes de previsión y los soportes institucionales de salud. Sus trabajos se llevan a cabo principalmente en establecimientos independientes, fuera de la esfera del hogar, en donde también aparecen de modo marginal los fenómenos de subcontratación y de forma masiva una alta estabilidad en el empleo. Pese a las garantías sociales y temporales ofrecidas por estos tipos de empleo asalariado formal, el $62 \%$ de estos trabajos se encuentran por debajo del sueldo mínimo, mientras que un $82 \%$ no sobrepasa los 300.000 pesos. De este modo, la marca de la dimensión insuficiencia es central en este grupo, además de su concentración en el sector privado de la economía.

La situación principal de las fracciones que componen este grupo se relaciona con la dependencia el sector privado: trabajadores de servicio y vendedores de comercio y mercados (21\%), oficiales y operarios de artes mecánicas y otros oficios (18,5\%), trabajadores no calificados (18\%), personal de apoyo administrativo (14\%) y operarios e instaladores de maquinaria (11\%) (véase el gráfico 12). Los Precarios de Insuficiencia Segura y Estable son un grupo con un $58 \%$ de hombres, mientras que las regiones con mayor presencia de casos pertenecientes a este conglomerado son Biobío, Atacama, Metropolitana y Los Ríos. Por último, las ramas más relevantes que se observan son comercio (20,5\%) e industria (15\%), aunque es importante señalar que este conglomerado se muestra distribuido a través de muchos sectores económicos.

\section{Gráfico 12}

Fracciones de clase en clúster PISE (N = 2.250.517)

(En porcentajes)

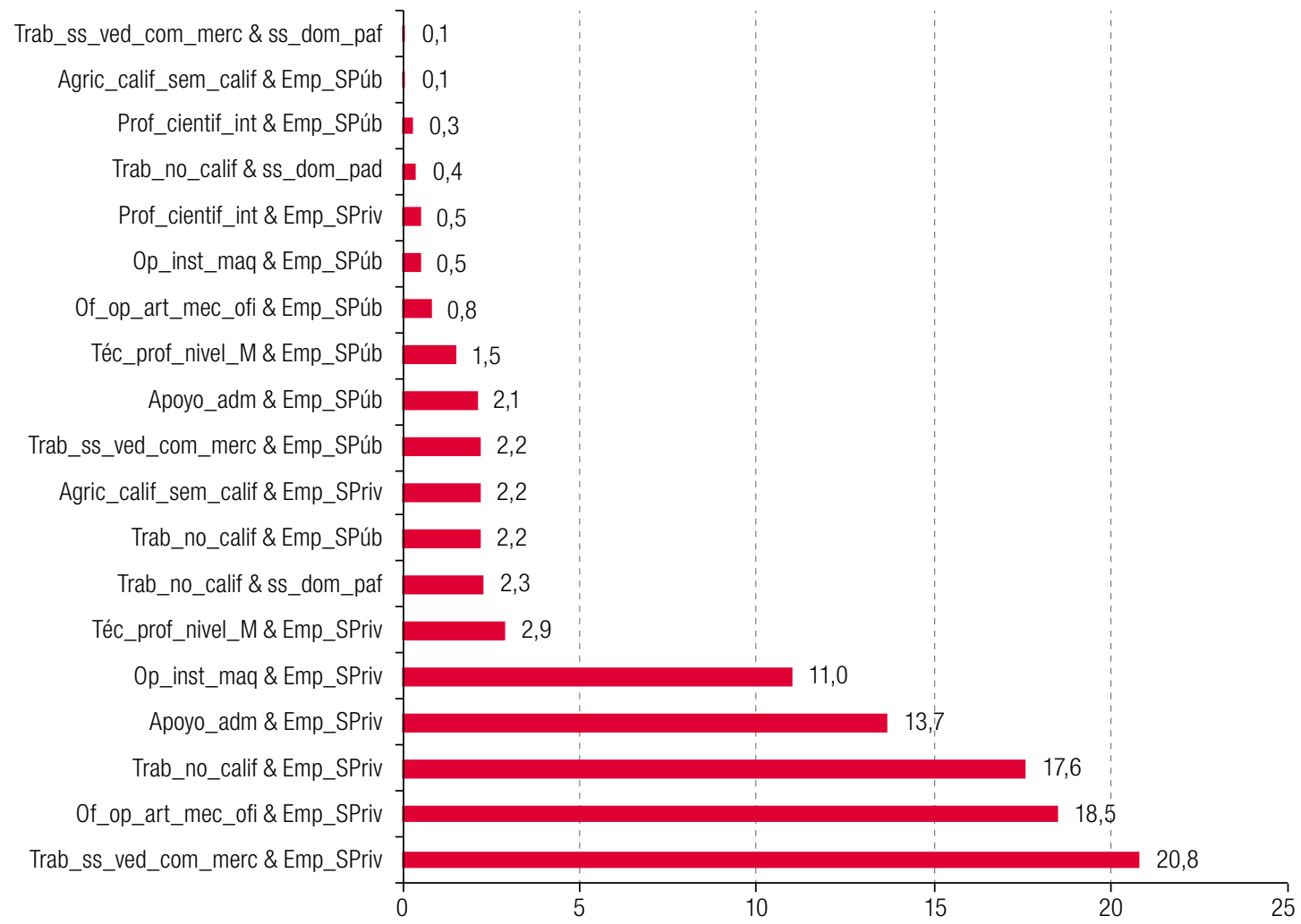

Fuente: Elaboración propia, sobre la base de la Encuesta de Caracterización Socioeconómica Nacional (CASEN) 2013. 


\section{g) Precarios Estacionales de Insuficiencia Salarial (PEIS)}

Este grupo alcanza el 9,5\% de los casos estudiados (véase gráfico 2): reúne trabajadores que se caracterizan por poseer una baja o nula calificación. Se desempeñan en el sector privado, en negocios que en su mayoría tienen un carácter estacional o temporal. Por ello, la predominancia de los contratos a plazo fijo señala una alta inestabilidad laboral, sumado a un sector $(28,5 \%)$ que no cuenta con un contrato firmado. Esta situación atípica en el empleo asalariado dependiente supone una frágil seguridad en materia de previsión, lo que no se ve completamente graficado en la estabilidad de las cotizaciones y sobre la irregularidad temporal de las condiciones laborales. Por último, este sector se afirma en la fragilidad del sistema de salud estatal (fondos A y B), asociándose a los ingresos de insuficiencia que registra mayoritariamente este grupo.

Los Precarios Estacionales de Insuficiencia Salarial son un conglomerado ampliamente compuesto por trabajadores dependientes en el sector privado: trabajadores no calificados (46\%), seguidos por agricultores calificados o semicalificados (16\%) y oficiales y operadores de artes mecánicas y otros oficios (13,5\%) (véase el gráfico 13). Con un 68\% de hombres, es un clúster que alcanza las cifras más altas en las regiones del Maule y O'Higgins, con la agricultura, caza y silvicultura como su rama económica más relevante (43\%), seguida de lejos por la construcción (15\%).

\section{Gráfico 13}

Fracciones de clase en clúster PEIS ( $\mathrm{N}=693.361)$

(En porcentajes)

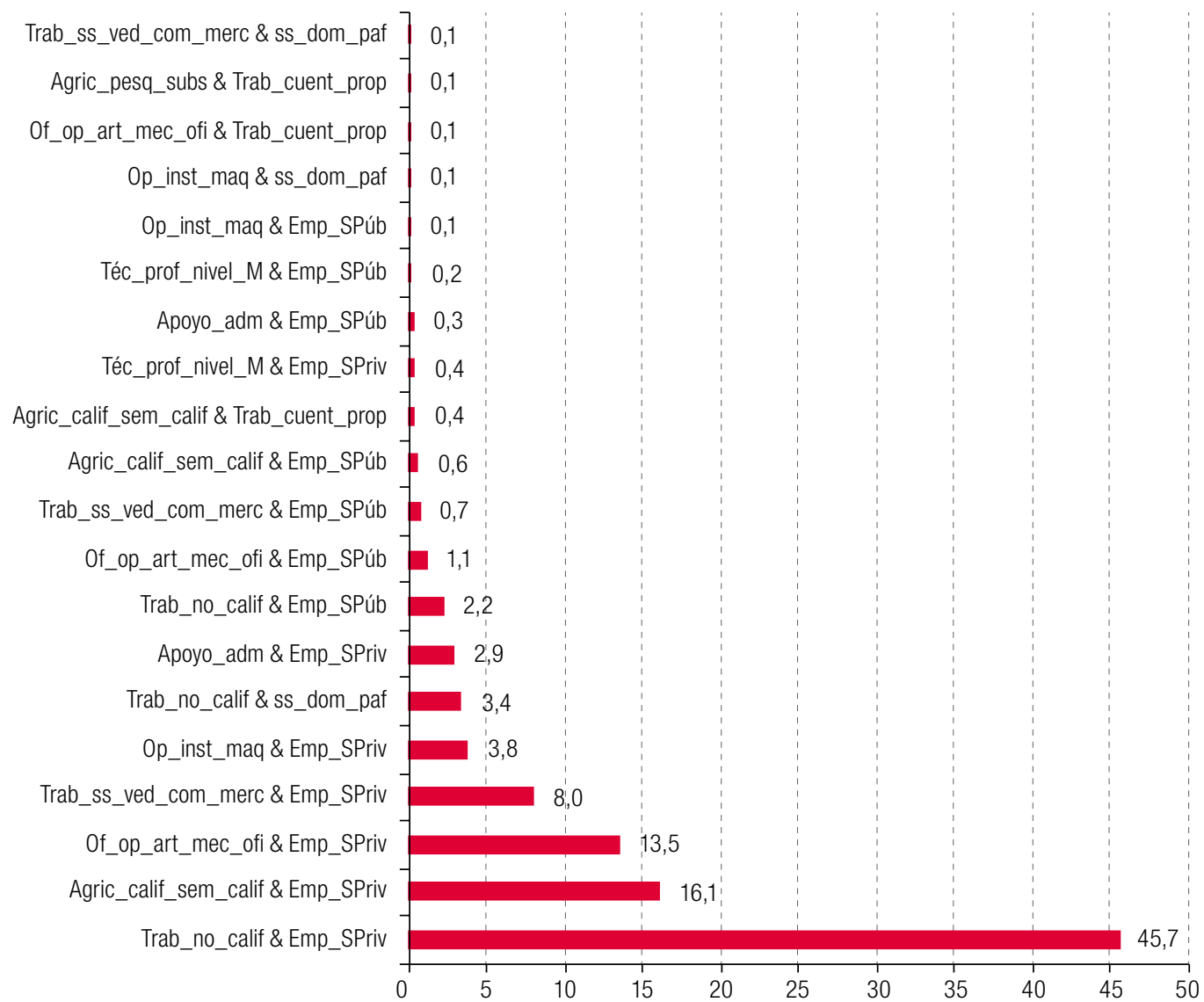

Fuente: Elaboración propia, sobre la base de la Encuesta de Caracterización Socioeconómica Nacional (CASEN) 2013. 


\section{h) Precarios de Alta Inseguridad y Estabilidad Relativa (PAIR)}

Este grupo alcanza un 10,3\% de los casos (véase gráfico 2), y está compuesto por trabajadores no calificados y no manuales de calificación baja o nula que se ubican en una zona gris de tránsito entre la estabilidad y la inestabilidad del trabajo. Este conglomerado se caracteriza por la predominancia de la falta de contrato y por una alta amenaza a la estabilidad del empleo. Por otra parte, la localización espacial de la actividad es heterogénea, lo que se explica en la participación de los servicios domésticos puertas afuera y la participación de trabajadores en la vía pública en el sector privado. Un elemento crítico que identifica a este grupo es la marcada falta de previsión y la inexistencia de cotización real de gran parte de sus integrantes (34,8\%). Además, estos trabajadores presentan una alta insuficiencia en los ingresos, concentrándose en los deciles II y III bajos, sin alcanzar un sueldo mínimo (79,1\%).

Estos trabajadores se concentran en el sector privado, donde trabajan de manera dependiente. Las fracciones de clases que caracterizan al clúster son los trabajadores no calificados, trabajadores y vendedores no cualificados y servicio doméstico puertas afuera (véase el gráfico 14). Se despeñan en las ramas de comercio (20\%) y servicios domésticos (19\%). Hombres y mujeres tienen una participación pareja. Están caracterizados por su pertenencia al sistema de FONASA (fondos A y B) y, pese a ser en su gran mayoría trabajadores asalariados dependientes, más de un $50 \%$ no se encuentra cotizando en el sistema previsional.

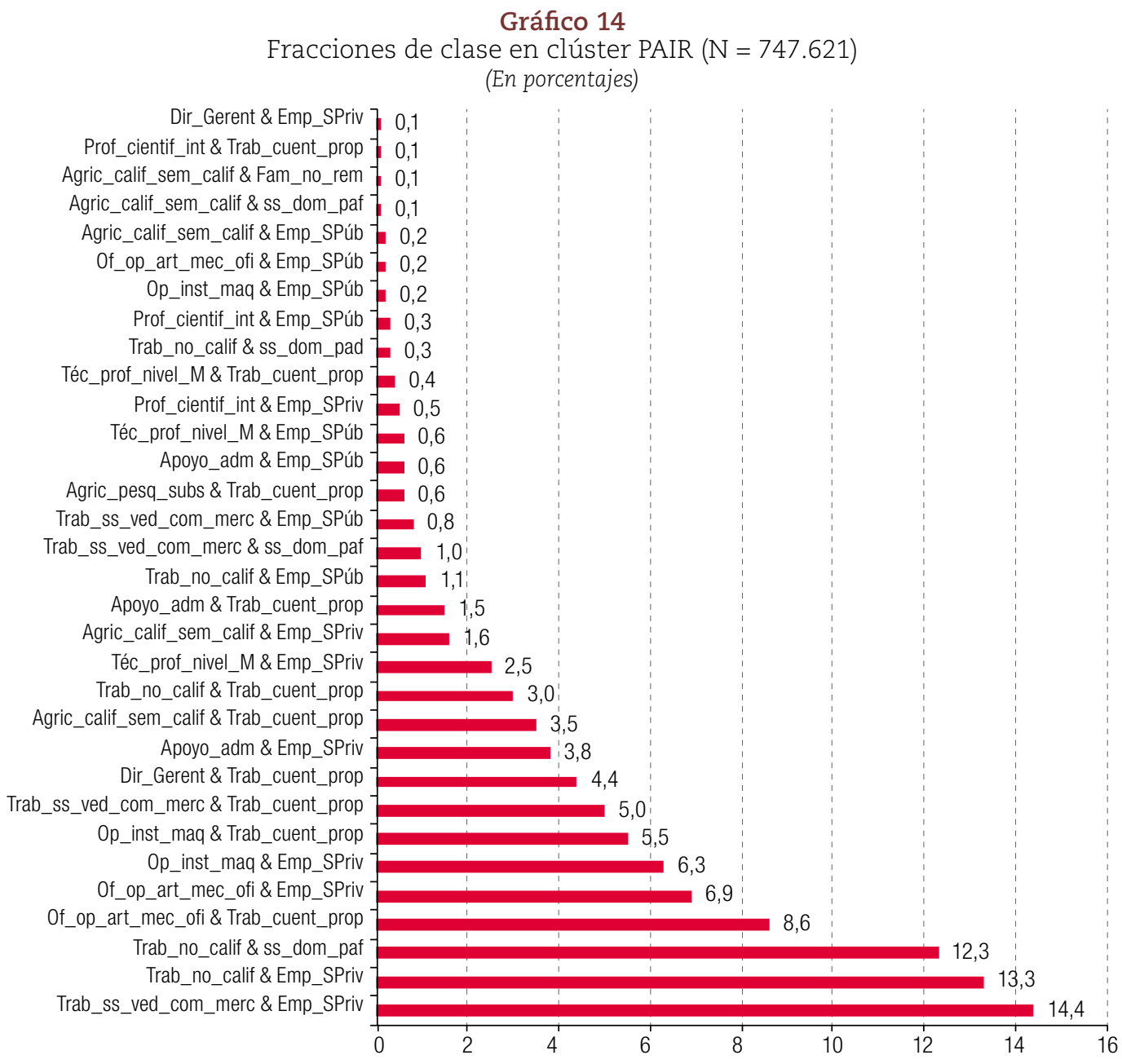

Fuente: Elaboración propia, sobre la base de la Encuesta de Caracterización Socioeconómica Nacional (CASEN) 2013. 


\section{i) Precarios Autónomos de Vulnerabilidad Sistémica (PAUV)}

Este grupo alcanza un 5,3\% del total (véase gráfico 2), y está compuesto por trabajadores por cuenta propia que cuentan con una calificación baja o nula y con perfiles que van de las actividades manuales a las no manuales. Los trabajos se mueven en la inestabilidad, con temporalidades cortas y con ausencia de contratos firmados. Este hecho puede relacionarse a una alta presencia de la subcontratación, junto con las prácticas de fragilización de los vínculos contractuales de parte de las empresas o los negocios principales.

La localización del trabajo es otro síntoma de la vulnerabilidad de este tipo de trabajos, ya que se realizan en espacios privados, como la vivienda propia y a domicilio, destacándose también la vía pública. Este clúster presenta proporcionalmente una mayor presencia de mujeres (65\%) y se concentra en las regiones de Araucanía, Coquimbo, y Arica y Parinacota. Más del $40 \%$ de sus integrantes se desempeña en la rama de comercio.

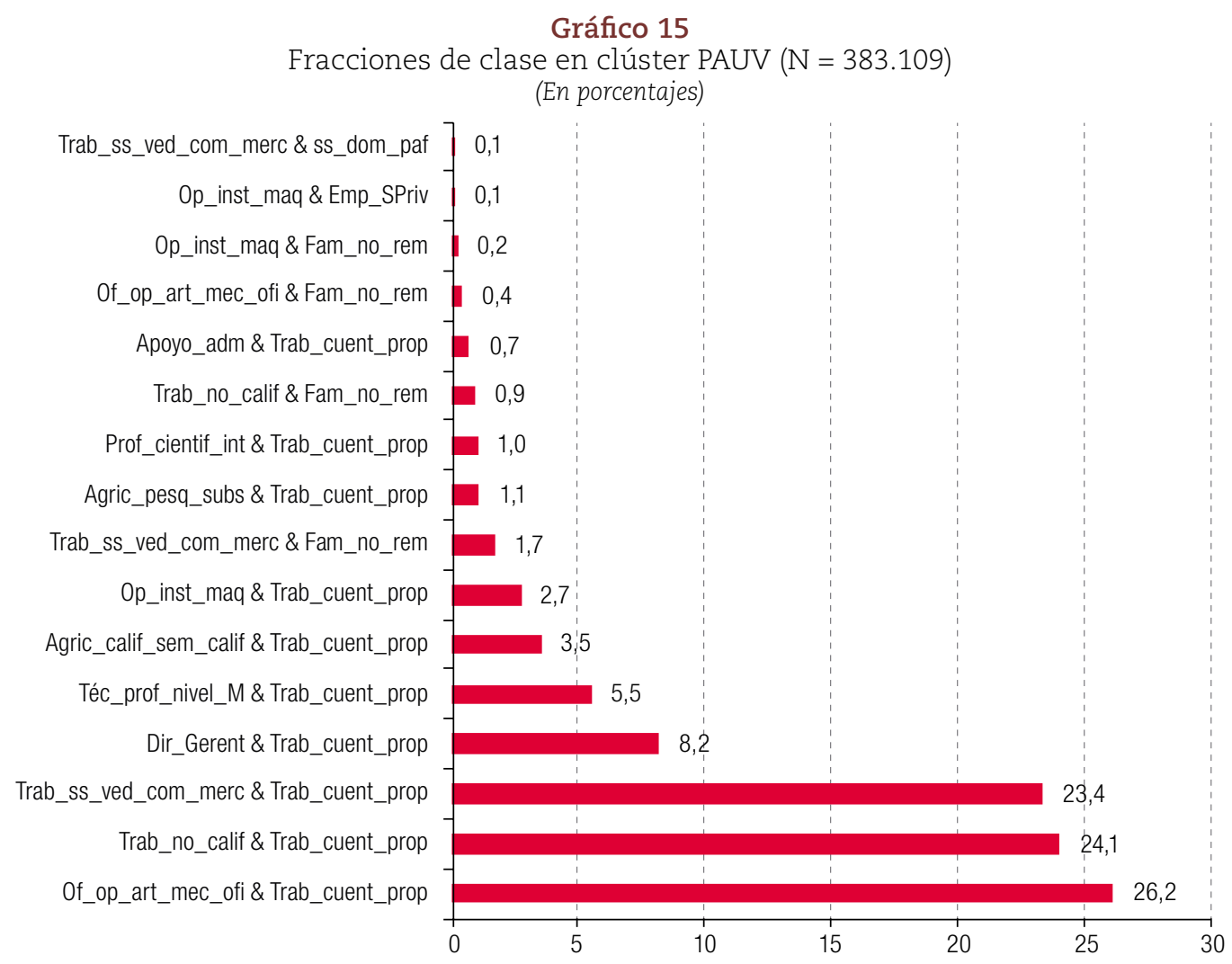

Fuente: Elaboración propia, sobre la base de la Encuesta de Caracterización Socioeconómica Nacional (CASEN) 2013.

Otra característica de este grupo es la alta inseguridad previsional y la inexistencia de una cotización real en el sistema de pensiones. Es uno de los grupos con mayor cantidad de trabajadores enfermos, aunque esta condición no se asocia directamente al trabajo y tiene su soporte en el fondo A del FONASA. Por último, el grupo se caracteriza por un ingreso principal que difícilmente llega a ubicarse por encima de la línea de pobreza e ingresos agrupados por trabajo (principal y secundario) que en la casi totalidad de los casos $(96,3 \%)$ no alcanzan los 171.000 pesos. Por todo lo anterior, estamos en presencia de un grupo que presenta una vulnerabilidad sistémica frente a las dimensiones de la precariedad del trabajo. 
Cuadro 12

Conglomerados y componente(s) de precariedad que poseen

\begin{tabular}{ll}
\hline Clúster & Componentes \\
\hline PIII & Inestabilidad, Inseguridad, Insuficiencia, Condiciones de trabajo, Cronopiedad. \\
\hline PEIS & Inestabilidad, Inseguridad, Insuficiencia, Condiciones de trabajo. \\
\hline PAUV & Inestabilidad, Inseguridad, Insuficiencia, Condiciones de trabajo. \\
\hline PAIR & Inestabilidad, Inseguridad, Insuficiencia, Condiciones de trabajo. \\
\hline PAIP & Inseguridad, Insuficiencia (intermedia), Condiciones de trabajo, Cronopiedad. \\
\hline PACUAS & Inestabilidad, Inseguridad (intermedia), Condiciones de trabajo, Cronopiedad. \\
\hline PROSI & Insuficiencia y Cronopiedad intermedias. \\
\hline PISE & Insuficiencia. \\
\hline PEAS & Cronopiedad.
\end{tabular}

Fuente: Elaboración propia.

Cuadro 13

Presencia de precariedad en los conglomerados

\begin{tabular}{|c|c|c|c|c|c|}
\hline & (In)estabilidad & (In)seguridad & (In)suficiencia & $\begin{array}{l}\text { Condiciones } \\
\text { de trabajo }\end{array}$ & Cronopiedad \\
\hline PEAS & + & + & + & + & $-1+$ \\
\hline PROSI & + & + & $-1+$ & + & $-1+$ \\
\hline PACUAS & - & $-1+$ & + & - & - \\
\hline PAUV & - & - & - & - & - \\
\hline PAIP & + & - & $-1+$ & - & - \\
\hline PIII & - & - & - & - & - \\
\hline PISE & + & + & - & + & + \\
\hline PEIS & - & + & - & - & + \\
\hline PAIR & - & - & - & - & + \\
\hline
\end{tabular}

Fuente: Elaboración propia.

Nota: (+) Indica situación positiva (de protección) en la dimensión; (-) Indica situación negativa (precariedad) en la dimensión, y $(-/+)$ Indica presencia relevante de la dimensión de precariedad, aunque no mayoritaria. 


\section{Gráfico 16}

Perfiles de precariedad, CIUOrec y CISErec en el espacio multidimensional

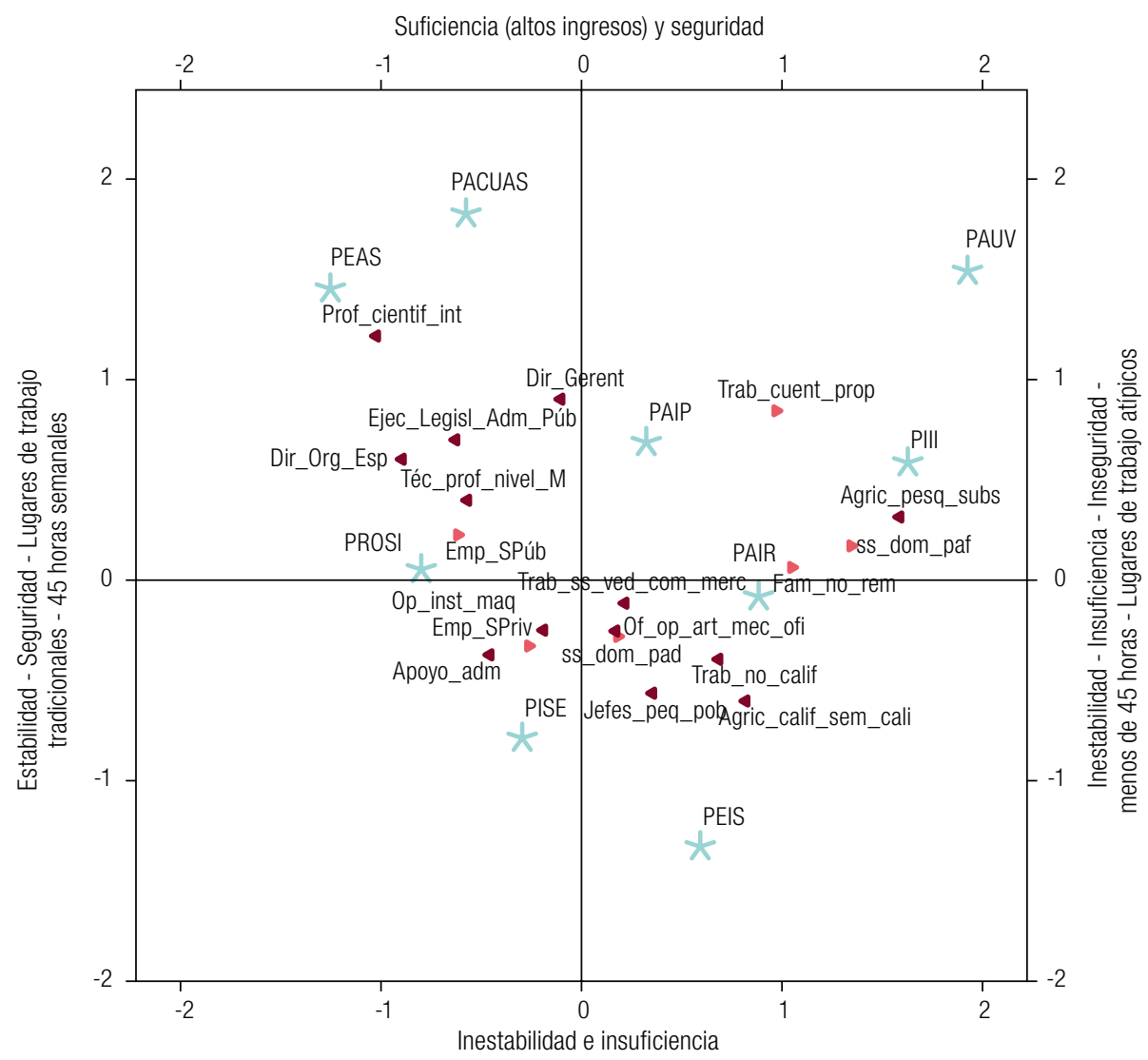

Fuente: Elaboración propia, sobre la base de la Encuesta de Caracterización Socioeconómica Nacional (CASEN) 2013.

\section{Conclusiones}

La precarización ligada al componente de la "(in)estabilidad" encarna situaciones vinculadas a la ausencia no solo de contratos de trabajo, sino también de cotización en el sistema previsional y de salud, bajos ingresos y una alta estacionalidad de los empleos, lo que vuelve inestables las actividades que se realizan y se combina en fracciones de clase con condición independiente y dependiente. El ejemplo más claro de ello lo encontramos en los conglomerados de Precarios Informales Inestables en Insuficiencia (PIII) y Precarios Estacionales de Insuficiencia Salarial (PEIS) ${ }^{9}$. También se encuentran rasgos de este tipo de precariedad en los Precarios de Alta Inseguridad y Estabilidad Relativa (PAIR) ${ }^{10}$ y, en menor medida, en los Precarios Autónomos de Vulnerabilidad Sistémica (PAUV) ${ }^{11}$ y los Precarios de Insuficiencia Segura y Estable (PISE) ${ }^{12}$.

\footnotetext{
9 Ambos grupos muestran una significativa presencia de precariedad en las cuatro variables de la dimensión de "(in)estabilidad": una importante presencia de trabajos no permanentes y de plazo fijo, ausencia de contratos escritos y subcontratación. Para la estimación del estadístico puntual de la muestra y de los parámetros poblacionales con sus intervalos de confianza al 95\% (véanse los cuadros A1.2, A1.3, A1.4 y A1.5).

${ }^{10}$ Con presencia significativa en trabajos no permanentes y de plazo fijo, y ausencia de contratos (véanse los cuadros A1.2, A1.3 y A1.4).

${ }^{11}$ Con precariedad de empleos no permanentes y subcontratación (véanse los cuadros A1.2 y A1.5).

12 Con precariedad únicamente en empleos de trabajo fijo (véase el cuadro A1.3).
} 
Una segunda cuestión de la precariedad está ligada al componente de la "(in)seguridad". La no cotización en el sistema previsional y en sistemas de salud es un elemento que marca aquellas actividades, principalmente independientes, con alta inestabilidad temporal del trabajo, bajos ingresos, lagunas previsionales e imposibilidad de acceder a planes de salud. Los clústeres más representativos de este componente son los Precarios Informales Inestables en Insuficiencia (PIII), los Precarios Autónomos de Vulnerabilidad Sistémica (PAUV) ${ }^{13}$, los Precarios de Alta Intensidad Permanente (PAIP) ${ }^{14}$ y, en menor medida, los Precarios de Alta Inseguridad y Estabilidad Relativa (PAIR) y los Precarios de Autonomía y Cualificación Superior (PACUAS) ${ }^{15}$.

El componente de la "(in)suficiencia" afecta aquellas actividades de bajos ingresos y se encuentra relacionado a todo un modelo de valorización de la fuerza de trabajo en el país (Julián, 2014) y a la proliferación de formas de trabajo sujetas a la pobreza. Su presencia casi transversal a la conformación de los clústeres indica una estructura de ingresos sujeta a la precariedad y a la falta de recursos económicos en la cotidianidad, interrogándonos sobre las estrategias económicoasociativas complementarias que permiten reproducir la fuerza de trabajo y vida. Los clústeres con promedios más bajos de ingresos son los Precarios Autónomos de Vulnerabilidad Sistémica (PAUV) y los Precarios Informales Inestables en Insuficiencia (PIII), a los que se suman los Precarios de Alta Inseguridad y Estabilidad Relativa (PAIR), los Precarios estacionales de insuficiencia salarial (PEIS) y los Precarios de Insuficiencia Segura y Estable (PISE) (véase el cuadro A1.9).

El cuarto componente son las "condiciones de trabajo". La variable que demostró mayor relevancia para describir la precariedad en esta dimensión fue el desempeño del trabajo en lugares atípicos (diferentes de fábricas u oficinas), que pueden ser el propio hogar del trabajador o cliente, talleres anexos a las viviendas, la vía pública, predios o faenas en espacios abiertos $u$ otros. Los grupos que muestran mayor presencia en este tipo de espacios son los Precarios Autónomos de Vulnerabilidad Sistémica (PAUV), los Precarios Informales Inestables en Insuficiencia (PIII), los Precarios de Alta Intensidad Permanente (PAIP), los Precarios Estacionales de Insuficiencia Salarial (PEIS), los Precarios de Alta Inseguridad y Estabilidad Relativa (PAIR) y los Precarios de Autonomía y Cualificación Superior (PACUAS) (véase el cuadro A1.10). Por su parte, las enfermedades o accidentes por motivos laborales son significativamente pocos en los nueve grupos estudiados.

En el caso de la "cronopiedad" se puede identificar la presencia de jornadas y tiempos de trabajo relacionados con fenómenos como el subempleo y la autonomía en la fijación de las horas de trabajo, así como sobrecargas y jornadas extensas, que van más allá de la jornada legal. De este modo, la diferenciación del tiempo de trabajo exhibe realidades heterogéneas. Por una parte, aparecen jornadas de alta duración que se realizan en marcos de trabajo independiente, lo que implica una inducción o una estrategia individual. No obstante, el trabajo independiente también evidencia jornadas exiguas. En los trabajos dependientes es posible que la protección vaya acompañada de jornadas extensas. En general, las jornadas más altas se observan en los Precarios de Alta Intensidad Permanente (PAIP) y los Protegidos Estables de Aseguramiento Superior (PEAS), mientras que las más bajas se observan en los Precarios Informales Inestables en Insuficiencia (PIII) y los Precarios Autónomos de Vulnerabilidad Sistémica (PAUV) (véase el cuadro A1.12).

Por último, a modo de resumen se pueden revisar los cuadros 11, 12 y 13, donde se exponen las principales dimensiones que configuran las precariedades y protecciones de cada grupo. De todo ello es posible concluir que nuestra tipología incluye una configuración de precariedades no solo ligadas a posiciones de clase más bajas, con ocupaciones de tipo manual y situaciones de empleo

\footnotetext{
${ }^{13}$ Los Precarios Informales Inestables en Insuficiencia (PIII) y los Precarios Autónomos de Vulnerabilidad Sistémica (PAUV) son dos conglomerados con un importante grado de no afiliación previsional y de ausencia de cotización efectiva (véanse los cuadros A1.6 y A1.7).

${ }^{14}$ Grupo con una marcada ausencia de cotización efectiva (véase el cuadro A1.7) y sin sistema de salud (véase el cuadro A1.8).

15 Estos dos últimos grupos con importante ausencia de cotización efectiva (véanse los cuadros A1.7 y A1.8).
} 
por cuenta propia, dependientes y otras formas no asalariadas, sino que también demuestra que la precariedad permea segmentos de clases trabajadoras medias y altas. Un primer ejemplo de ello es el caso del clúster de los Precarios de Autonomía y Cualificación Superior (PACUAS), un pequeño grupo $(1,8 \%)$ de trabajadores de altos ingresos, altamente calificados, que poseen significativas debilidades relativas a una mayoría de casos en situación por cuenta propia, así como ejerciendo labores en lugares de trabajo atípicos (en la vivienda, talleres o locales anexos a la vivienda, y otros). El otro grupo de trabajadores de segmentos medios y altos son los Protegidos Estables de Aseguramiento Superior (PEAS), quienes, pese a ser protegidos en diferentes aspectos, poseen el tercer promedio de jornada laboral más extensa. De este modo, los procesos de precarización -en sus diversas dimensionesse han vuelto transversales no solo a los segmentos de baja cualificación, sino también a actividades tradicionalmente cargadas de mayor estatus, obligando a estos grupos de trabajadores no manuales a experimentar procesos de adaptación y subsistencia en medio de una fuerte inestabilidad y rotación laboral. Todo esto muestra niveles de precariedades distribuidos en diferentes clases sociales, ocupaciones (calificadas y no calificadas) y situaciones de empleo (autónomas, dependientes en el sector privado, dependientes en el sector público y otras).

En suma, la precariedad como condición multidimensional se expresa como un fenómeno transversal y transclasista, que recorre los distintos rincones del mercado laboral chileno. Las consecuencias e impactos sociales de la precariedad se expresan en la desigualdad, la insuficiencia, la ausencia de derechos y la persistencia de desprotección social en las que vive buena parte de la población trabajadora. Estas precariedades laborales podrían ser consideradas como la viga maestra de una sociedad alejada de proyectos sociopolíticos centrados en el bienestar, una sociedad precaria ante la cual se deben visibilizar las consecuencias de dicha precariedad y diseñar mecanismos para mejorar las oportunidades de vida de su población. 


\section{Bibliografía}

Antunes, R. (2005), Los sentidos del trabajo. Ensayo sobre la afirmación y la negación del trabajo, Buenos Aires, Herramienta.

(2001), ¿Adiós al trabajo? Ensayo sobre las metamorfosis y el rol central del mundo del trabajo, São Paulo, Cortez.

Auer, P. y S. Cazes (2000), "The resilience of the long-term employment relationship: evidence from the industrialized countries", International Labour Review, vol. 139, № 4, Hoboken, Wiley.

Aravena, A. (2016), "La recuperación de los estudios laborales en Chile (1990-2014)", Los estudios laborales en América Latina: orígenes, desarrollo y perspectivas, E. de la Garza (ed.), Ciudad de México, Siglo XXI.

Archer, M. (2009), Teoría social realista. El enfoque morfogenético, Santiago, Universidad Alberto Hurtado.

Barattini, M. (2009), “El trabajo precario en la era de la globalización. ¿Es posible la organización?”, Polis, vol. 8, № 24, Santiago, Universidad Bolivariana.

Beck, U. (2000), Un nuevo mundo feliz: la precariedad del trabajo en la era de la globalización, Barcelona, Paidós.

Blanco, O. (2019), "Trabajo, territorios y desigualdad: La propuesta de las tipologías de clases geográficamente situadas", tesis para optar al grado de Doctor en Sociología, Santiago, Universidad Alberto Hurtado. (2016), "Clases, desarrollo geográfico desigual y capitalismo periférico-dependiente: una aproximación desde el caso chileno", Pléyade, № 18, Santiago, Centro de Análisis e Investigación Política (CAIP).

Boltanski, L. y E. Chiapello (2002), El nuevo espíritu del capitalismo, Madrid, Akal.

Bourdieu, P. (2011), Las estrategias de la reproducción social, Buenos Aires, Siglo XXI. (2007), Razones prácticas, Madrid, Anagrama.

(2003), Cuestiones de sociología, Madrid, Istmo.

_(2002), "Condición de clase y posición de clase", Revista Colombiana de Sociología, vol. 7, № 1, Bogotá, Universidad Nacional de Colombia.

- (2001), "¿Cómo se hace una clase social? Sobre la existencia teórica y práctica de los grupos", Poder, derecho y clases sociales, Bilbao, Desclée de Brouwer.

_ (1994), "Espacio social y génesis de las clases", Sociología y cultura, Ciudad de México, Grijalbo.

Boyer, R. (2007), Crisis y regímenes de crecimiento: una introducción a la teoría de la regulación, Buenos Aires, Miño y Dávila.

Butler, J. (2004), Precarious life: the powers of mourning and violence, Londres, Verso.

Castel, R. (2010), El ascenso de las incertidumbres: trabajo, protecciones, estatuto del individuo, Buenos Aires, Fondo de Cultura Económica. (2004), La inseguridad social. ¿Qué es estar protegido?, Buenos Aires, Manantial.

Castel, R. y K. Dörre (2009), Prekarität, Abstieg, Ausgrenzung: Die soziale Frage am Beginn des 21. Jahrhunderts, Frankfurt, Campus.

Crompton, R. (1994), Clase y estratificación. Una introducción a los debates actuales, Madrid, Tecnos.

De la Garza, E. (2001), "Problemas clásicos y actuales de la crisis del trabajo", El futuro del trabajo. El trabajo del futuro, E. de la Garza y J. Neffa (coords.), Buenos Aires, Consejo Latinoamericano de Ciencias Sociales (CLACSO).

(2000), "La flexibilidad del trabajo en América Latina", Tratado latinoamericano de sociología del trabajo, E. de la Garza (coord.), Ciudad de México, Fondo de Cultura Económica.

Dörre, K. (2009), "La precariedad: ¿centro de la cuestión social en el siglo XXI?", Actuel Marx Intervenciones, $N^{\circ} 8$, Santiago, LOM Ediciones.

Echeverría, M. y D. López (2004), Flexibilidad laboral en Chile: las empresas y las personas, Santiago, Dirección del Trabajo.

Escofier, B. y J. Pagès (1992), Análisis factoriales simples y múltiples: objetivos, métodos e interpretación, Bilbao, Universidad del País Vasco.

Escoto, A. (2010), "Precariedad laboral juvenil en El Salvador, 2003-2007", tesis para optar al grado de magister, Ciudad de México, Facultad Latinoamericana de Ciencias Sociales (FLACSO).

Esping-Andersen, G. y M. Regini (eds.) (2000), Why Deregulate Labour Markets? Oxford, Oxford University Press.

Fernández, M. (2014), "Dimensiones de la precariedad laboral: un mapa de las características del empleo sectorial en la Argentina", Revista Cuadernos de Economía, vol. 33, № 62, Bogotá, Universidad Nacional de Colombia.

Ferrán, M. (2001), SPSS para Windows: análisis estadístico, Madrid, McGraw-Hill.

Fitoussi, J. y P. Rosanvallon (1997), La nueva era de las desigualdades, Buenos Aires, Manantial. 
Frege, C. y J. Kelly (2003), "Union revitalization strategies in comparative perspective", European Journal of Industrial Relations, vol. 9, № 1, Thousand Oaks, Sage.

Gálvez, T. (2001), "Para reclasificar el empleo: lo clásico y lo nuevo", Cuaderno de Investigación, № 14, Santiago, Dirección del Trabajo.

Giddens, A. (1996), Las estructuras de clases en las sociedades avanzadas, Madrid, Alianza.

Goldthorpe, J. (2010), De la sociología: números, narrativas e integración de la investigación y la teoría, Madrid, Centro de Investigaciones Sociológicas (CIS).

González, J. y J. Carabaña (1992), "La construcción empírica de las clases", Política y Sociedad, №11, Madrid, Universidad Nacional de Educación a Distancia (UNED).

Grau, A. y L. Lexartza (2010), Precariedad laboral en Centroamérica: impacto para las mujeres, San José, Fundación Friedrich Ebert.

Grusky, D. y J. Sørensen (1998), "Can class analysis be salvaged?", American Journal of Sociology, vol. 103, $N^{\circ} 5$, Chicago, The University of Chicago Press.

Grusky, D. y K. Weeden (2005), "The case for a new class map", American Journal of Sociology, vol. 111, $N^{\circ} 1$, Chicago, The University of Chicago Press.

Grusky, D., K. Weeden y J. Sørensen (2001), "The case for realism in class analysis", Political Power and Social Theory, D. Davis (ed.), Bingley, Emerald Group Publishing Limited.

Guadamarra, R., A. Hualde y S. López (coords.) (2015), La precariedad laboral en México: dimensiones, dinámicas y significados, Ciudad de México, El Colegio de la Frontera Norte/Universidad Autónoma Metropolitana (UAM).

Julián, D. (2017), "Precariedad laboral en América Latina: contribuciones para un modelo para armar", Revista Colombiana de Sociología, vol. 40, № 2, Bogotá, Universidad Nacional de Colombia.

(2014), "Bases del modelo de valoración precario del trabajo en Chile. Acercamientos desde la política laboral y la cultura del trabajo", Sociológica, vol. 29, N 81, Ciudad de México, Universidad Autónoma Metropolitana (UAM).

Kalleberg, A. (2011), Good Jobs, Bad Jobs: The Rise of Polarized and Precarious Employment Systems in the United States, 1970s to 2000s, Nueva York, Russell Sage Foundation.

Le Roux, B. y H. Rouanet (2010), Multiple Correspondence Analysis, Thousand Oaks, Sage.

Lorey, I. (2015), State of Insecurity, Londres, Verso.

Marín, E. (2013), "Precarious work: an international problem", International Journal of Labour Research, vol. 5, $N^{\circ}$ 1, Ginebra, Organización Internacional del Trabajo (OIT).

Marx, K. (1971), Introducción general a la crítica de la economía política, Buenos Aires, Cuadernos del Pasado y Presente.

Monteforte, E. (2012), "Precariedad laboral: debate sobre su contenido y formas de medición", Segundas Jornadas Nacionales sobre Estudios Regionales y Mercados de Trabajo, Universidad Nacional del Litoral, 4-5 julio.

Mora Salas, M. (2010), Ajuste y empleo: la precarización del trabajo asalariado en la era de la globalización, Ciudad de México, El Colegio de México.

Neffa, J. (2010), "La transición desde los 'verdaderos empleos' al trabajo precario", E. de la Garza y J. Neffa (coords.), Trabajo, identidad y acción colectiva, Ciudad de México, Universidad Autónoma Metropolitana (UAM)/Consejo Latinoamericano de Ciencias Sociales (CLACSO)/Plaza y Valdés.

Paugam, S. y. Zhou (2007), "Job insecurity”, Employment Regimes and the Quality of Work, D. Gallie (ed.), Oxford, Oxford University Press.

Palomino, H. (2001), "Trabajo y teoría social: conceptos clásicos y tendencias contemporáneas", Revista de Ciencias Sociales, № 17, Montevideo, Universidad de la República.

Pérez, C. (2004), Técnicas de análisis multivariante de datos. Aplicaciones con SPSS, Madrid, Pearson.

Ramos, C. (2009), La transformación de la empresa chilena. Una modernización desbalanceada, Santiago, Universidad Alberto Hurtado.

Ross, A. (2008), "The new geography of work: power to the precarious?", Theory, Culture \& Society, vol. 25, $N^{\circ} 7-8$, Thousand Oaks, Sage.

Rubio, J. (2010), "Precariedad laboral en México. Una propuesta de medición integral", Revista Enfoques, vol. 8, No 13, Santiago, Universidad Central de Chile.

Thompson, P. y D. van den Broek (2010), "Managerial control and workplace regimes: an introduction", Work, Employment and Society, vol. 24, № 3, Thousand Oaks, Sage.

Van der Linden, M. (2014), "Santo Precario: a new inspiration for labor historians", Labor. Studies in WorkingClass History of the Americas, vol. 11, $\mathrm{N}^{\circ} 1$.

Visauta, B. y J. Martori (2003), Análisis estadístico con SPSS para Windows, vol. II, Madrid, McGraw-Hill.

Wright, E. (1994), Clases, Madrid, Siglo XXI. 


\section{Anexo A1}

Cuadro A1.1

Grupos de precariedad según variables de inestabilidad, inseguridad, condiciones de trabajo y cronopiedad

(En porcentajes)

\begin{tabular}{|c|c|c|c|c|c|c|c|c|c|c|}
\hline & & PIII & PAIP & PISE & PEAS & PEIS & PAIR & PAUV & PACUAS & PROSI \\
\hline \multirow{6}{*}{$\begin{array}{l}\text { ¿Su trabajo } \\
0 \text { negocio } \\
\text { principal es } \\
\text { de tipo...? }\end{array}$} & Permanente & 54,1 & 82,9 & 89,9 & 97,5 & 31,4 & 71,3 & 44,3 & 86,0 & 94,2 \\
\hline & $\begin{array}{l}\text { De temporada } 0 \\
\text { estacional }\end{array}$ & 17,5 & 3,4 & 2,7 & 0,5 & 42,9 & 11,7 & 8,1 & 2,9 & 1,5 \\
\hline & Ocasional o eventual & 25,0 & 10,1 & 0,9 & 0,2 & 4,0 & 10,4 & 46,7 & 9,1 & 0,6 \\
\hline & A prueba & 0,3 & 1,6 & 0,5 & 0,0 & 2,8 & 1,2 & 0,2 & 0,1 & 0,2 \\
\hline & Por plazo & 3,0 & 2,0 & 5,9 & 1,8 & 18,9 & 5,4 & 0,7 & 1,9 & 3,6 \\
\hline & Total & 100,0 & 100,0 & 100,0 & 100,0 & 100,0 & 100,0 & 100,0 & 100,0 & 100,0 \\
\hline \multirow{3}{*}{$\begin{array}{l}\text { Tipo de } \\
\text { contrato }\end{array}$} & Plazo indefinido & 30,9 & 49,2 & 83,7 & 93,0 & 22,6 & 56,4 & 18,0 & 78,2 & 89,7 \\
\hline & Plazo fijo & 69,1 & 50,8 & 16,3 & 7,0 & 77,4 & 43,6 & 82,0 & 21,8 & 10,3 \\
\hline & Total & 100,0 & 100,0 & 100,0 & 100,0 & 100,0 & 100,0 & 100,0 & 100,0 & 100,0 \\
\hline \multirow{5}{*}{$\begin{array}{l}\text { Contrato de } \\
\text { trabajo escrito }\end{array}$} & Sí, firmó & 4,9 & 54,2 & 96,2 & 97,5 & 64,5 & 37,7 & 0,0 & 74,5 & 96,5 \\
\hline & Sí, pero no ha firmado & 2,0 & 1,3 & 0,7 & 0,6 & 3,6 & 3,0 & 10,9 & 3,6 & 1,1 \\
\hline & No tiene & 91,1 & 42,1 & 2,2 & 1,6 & 28,6 & 56,1 & 89,1 & 18,9 & 1,7 \\
\hline & $\begin{array}{l}\text { No se acuerda o no } \\
\text { sabe si firmó contrato }\end{array}$ & 2,0 & 2,4 & 0,9 & 0,4 & 3,4 & 3,2 & 0,0 & 3,0 & 0,6 \\
\hline & Total & 100,0 & 100,0 & 100,0 & 100,0 & 100,0 & 100,0 & 100,0 & 100,0 & 100,0 \\
\hline \multirow{4}{*}{$\begin{array}{l}\text { ¿Con quién } \\
\text { firmó su } \\
\text { contrato o } \\
\text { estableció } \\
\text { su acuerdo } \\
\text { de trabajo? }\end{array}$} & $\begin{array}{l}\text { Directamente con la } \\
\text { empresa o negocio } \\
\text { donde trabaja }\end{array}$ & 96,5 & 98,4 & 89,2 & 98,5 & 81,4 & 93,9 & 73,7 & 100,0 & 94,6 \\
\hline & $\begin{array}{l}\text { Con un contratista } \\
\text { o subcontratista de } \\
\text { bienes o servicios }\end{array}$ & 2,6 & 1,6 & 10,0 & 1,4 & 16,7 & 5,5 & 26,3 & 0,0 & 5,1 \\
\hline & $\begin{array}{l}\text { Con empresa } \\
\text { de servicios transitorios, } \\
\text { suministradora } \\
\text { de trabajadores } \\
\text { o contratista laboral }\end{array}$ & 0,9 & 0,0 & 0,7 & 0,1 & 1,9 & 0,6 & 0,0 & 0,0 & 0,3 \\
\hline & Total & 100,0 & 100,0 & 100,0 & 100,0 & 100,0 & 100,0 & 100,0 & 100,0 & 100,0 \\
\hline \multirow{3}{*}{$\begin{array}{l}\text { Sistema } \\
\text { previsional }\end{array}$} & Sí & 47,5 & 65,8 & 98,9 & 99,0 & 91,3 & 74,4 & 43,0 & 76,9 & 98,8 \\
\hline & No & 52,5 & 34,2 & 1,1 & 1,0 & 8,7 & 25,6 & 57,0 & 23,1 & 1,2 \\
\hline & Total & 100,0 & 100,0 & 100,0 & 100,0 & 100,0 & 100,0 & 100,0 & 100,0 & 100,0 \\
\hline \multirow[t]{8}{*}{$\begin{array}{l}\text { Cotiza en } \\
\text { algún sistema } \\
\text { previsional }\end{array}$} & $\begin{array}{l}\text { Sí, AFP. Cotización } \\
\text { obligatoria del trabajador } \\
\text { dependiente }\end{array}$ & 4,5 & 23,9 & 96,1 & 89,3 & 76,9 & 35,4 & 3,1 & 30,9 & 93,1 \\
\hline & $\begin{array}{l}\text { Sí, AFP. Cotización } \\
\text { voluntaria del trabajador } \\
\text { independiente }\end{array}$ & 3,0 & 22,0 & 0,4 & 2,7 & 0,5 & 4,2 & 4,7 & 39,0 & 1,0 \\
\hline & $\begin{array}{l}\text { Si, IPS ex INP. Caja } \\
\text { de EE. Públicos, } \\
\text { Particulares, SSS u otras }\end{array}$ & 1,2 & 0,4 & 0,4 & 0,3 & 0,6 & 1,5 & 1,4 & 0,5 & 0,4 \\
\hline & $\begin{array}{l}\text { Sí, Caja de Previsión de } \\
\text { la Defensa Nacional }\end{array}$ & 0,1 & 0,7 & 0,1 & 2,6 & 0,0 & 0,1 & 0,2 & 0,8 & 0,8 \\
\hline & $\begin{array}{l}\text { Sí, Dirección de Previsión } \\
\text { de Carabineros }\end{array}$ & 0,0 & 0,4 & 0,0 & 2,7 & 0,0 & 0,0 & 0,4 & 1,0 & 0,5 \\
\hline & Sí, otra. Especifique & 0,0 & 0,5 & 0,1 & 0,3 & 0,0 & 0,1 & 0,1 & 0,5 & 0,2 \\
\hline & No está cotizando & 91,1 & 52,1 & 3,0 & 2,0 & 22,0 & 58,6 & 90,0 & 27,2 & 4,0 \\
\hline & Total & 100,0 & 100,0 & 100,0 & 100,0 & 100,0 & 100,0 & 100,0 & 100,0 & 100,0 \\
\hline
\end{tabular}


Cuadro A1.1 (conclusión)

\begin{tabular}{|c|c|c|c|c|c|c|c|c|c|c|}
\hline & & PIII & PAIP & PISE & PEAS & PEIS & PAIR & PAUV & PACUAS & PROSI \\
\hline \multirow[t]{10}{*}{ Salud } & FONASA A & 66,5 & 24,6 & 6,7 & 0,5 & 27,4 & 40,2 & 59,1 & 4,0 & 1,9 \\
\hline & FONASA B & 17,6 & 24,3 & 38,5 & 2,6 & 47,0 & 32,0 & 20,1 & 8,5 & 10,5 \\
\hline & FONASA C & 3,1 & 5,8 & 28,9 & 1,8 & 12,8 & 7,6 & 3,6 & 4,1 & 15,1 \\
\hline & FONASA D & 1,7 & 5,4 & 12,6 & 9,1 & 3,3 & 4,1 & 3,4 & 7,1 & 29,5 \\
\hline & FONASA No sabe grupo & 2,0 & 5,6 & 8,9 & 1,6 & 5,0 & 4,1 & 3,0 & 2,8 & 7,0 \\
\hline & FF.AA. y del Orden & 0,5 & 2,2 & 0,3 & 5,8 & 0,0 & 0,5 & 1,4 & 3,6 & 2,6 \\
\hline & ISAPRE & 1,1 & 17,5 & 2,3 & 77,6 & 0,1 & 2,9 & 3,7 & 61,6 & 31,0 \\
\hline & Ninguno & 6,6 & 13,6 & 0,5 & 0,6 & 3,0 & 7,6 & 5,2 & 7,4 & 1,3 \\
\hline & Otro sistema & 0,7 & 0,9 & 1,3 & 0,3 & 1,3 & 1,0 & 0,5 & 0,7 & 0,9 \\
\hline & Total & 100,0 & 100,0 & 100,0 & 100,0 & 100,0 & 100,0 & 100,0 & 100,0 & 100,0 \\
\hline \multirow{10}{*}{$\begin{array}{l}\text { Lugar en } \\
\text { donde realiza } \\
\text { la actividad } \\
\text { o se ubica } \\
\text { el negocio }\end{array}$} & Dentro de su vivienda & 7,6 & 17,2 & 0,3 & 0,4 & 0,1 & 1,7 & 33,0 & 22,4 & 0,7 \\
\hline & $\begin{array}{l}\text { Taller o local anexo } \\
\text { a su vivienda }\end{array}$ & 6,3 & 17,5 & 1,0 & 0,8 & 0,6 & 4,0 & 8,3 & 8,4 & 0,9 \\
\hline & $\begin{array}{l}\text { En un establecimiento } \\
\text { independiente (fábrica, } \\
\text { oficina, etc.) }\end{array}$ & 13,4 & 34,0 & 73,2 & 86,1 & 29,8 & 39,7 & 7,5 & 49,7 & 77,4 \\
\hline & En un predio agrícola & 16,8 & 2,1 & 2,4 & 0,5 & 41,7 & 8,1 & 2,7 & 0,8 & 0,5 \\
\hline & En un predio marítimo & 1,5 & 0,4 & 1,0 & 0,4 & 1,0 & 1,0 & 0,6 & 0,2 & 0,8 \\
\hline & $\begin{array}{l}\text { A domicilio (casa del } \\
\text { empleador o cliente) }\end{array}$ & 31,6 & 8,8 & 4,7 & 1,0 & 7,7 & 23,9 & 19,1 & 5,8 & 1,7 \\
\hline & $\begin{array}{l}\text { En la vía pública, } \\
\text { transporte terrestre, } \\
\text { aéreo o acuático }\end{array}$ & 18,3 & 15,5 & 5,9 & 2,3 & 5,5 & 15,0 & 22,2 & 6,5 & 7,0 \\
\hline & $\begin{array}{l}\text { En faena, obras } \\
\text { de construcción, } \\
\text { mineras o similares }\end{array}$ & 1,8 & 1,9 & 10,3 & 7,0 & 12,9 & 4,3 & 0,6 & 2,3 & 9,8 \\
\hline & En otro lugar & 2,7 & 2,6 & 1,2 & 1,4 & 0,8 & 2,2 & 5,9 & 3,8 & 1,2 \\
\hline & Total & 100,0 & 100,0 & 100,0 & 100,0 & 100,0 & 100,0 & 100,0 & 100,0 & 100,0 \\
\hline \multirow[t]{6}{*}{$\begin{array}{l}\text { Enfermedad } \\
0 \text { accidente }\end{array}$} & $\begin{array}{l}\text { Sí, enfermedad provocada } \\
\text { por el trabajo }\end{array}$ & 2,6 & 2,7 & 3,3 & 3,8 & 2,3 & 2,3 & 3,1 & 3,4 & 3,5 \\
\hline & $\begin{array}{l}\text { Sí, enfermedad no } \\
\text { provocada por el trabajo }\end{array}$ & 14,4 & 14,5 & 11,8 & 14,0 & 10,4 & 13,8 & 19,9 & 12,3 & 12,1 \\
\hline & $\begin{array}{l}\text { Sí, accidente laboral } \\
\text { o escolar }\end{array}$ & 0,6 & 0,2 & 0,7 & 0,6 & 0,8 & 0,7 & 0,3 & 0,4 & 0,5 \\
\hline & $\begin{array}{l}\text { Sí, accidente no } \\
\text { laboral ni escolar }\end{array}$ & 1,5 & 1,2 & 0,8 & 1,0 & 0,7 & 0,8 & 2,1 & 0,9 & 0,9 \\
\hline & $\begin{array}{l}\text { No tuvo ninguna } \\
\text { enfermedad } 0 \text { accidente }\end{array}$ & 80,9 & 81,3 & 83,3 & 80,6 & 85,8 & 82,4 & 74,7 & 83,0 & 83,0 \\
\hline & Total & 100,0 & 100,0 & 100,0 & 100,0 & 100,0 & 100,0 & 100,0 & 100,0 & 100,0 \\
\hline \multirow{4}{*}{$\begin{array}{l}\text { Horas de } \\
\text { trabajo }\end{array}$} & $<=44$ & 66,8 & 46,9 & 18,1 & 33,9 & 19,7 & 47,7 & 84,5 & 47,7 & 25,2 \\
\hline & $45-45$ & 10,5 & 12,8 & 60,7 & 41,8 & 61,3 & 23,4 & 3,0 & 16,8 & 50,9 \\
\hline & $46+$ & 22,7 & 40,3 & 21,2 & 24,4 & 19,1 & 28,9 & 12,5 & 35,5 & 23,8 \\
\hline & Total & 100,0 & 100,0 & 100,0 & 100,0 & 100,0 & 100,0 & 100,0 & 100,0 & 100,0 \\
\hline
\end{tabular}

Fuente: Elaboración propia, sobre la base de la Encuesta de Caracterización Socioeconómica Nacional (CASEN) 2013. 
Cuadro A1.2

Estimación de parámetros trabajos no permanentes

\begin{tabular}{lccccc}
\hline Clúster & $\mathbf{N}$ & $\begin{array}{c}\text { Estimación puntual } \\
\text { de la proporción } \\
\text { (en porcentajes) }\end{array}$ & $\begin{array}{c}\text { Desviación estándar } \\
\text { (en porcentajes) }\end{array}$ & \multicolumn{2}{c}{$\begin{array}{c}95 \% \text { de intervalo de confianza } \\
\text { (en porcentajes) }\end{array}$} \\
\cline { 6 - 7 } PIII & 568907 & 45,67 & 49,81 & Inferior & Superior \\
\hline PAIP & 359923 & 17,01 & 37,57 & 16,54 & 45,80 \\
\hline PISE & 2250517 & 10,05 & 30,07 & 10,01 & 17,13 \\
\hline PEAS & 876645 & 2,51 & 15,64 & 2,48 & 2,54 \\
\hline PEIS & 693361 & 68,42 & 46,48 & 68,31 & 68,53 \\
\hline PAIR & 747621 & 28,54 & 45,16 & 28,44 & 28,64 \\
\hline PAUV & 383109 & 54,72 & 49,78 & 54,56 & 54,87 \\
\hline PACUAS & 134118 & 13,90 & 34,59 & 13,71 & 14,08 \\
\hline PROSI & 1263558 & 5,78 & 23,33 & 5,73 & 5,82 \\
\hline
\end{tabular}

Fuente: Elaboración propia, sobre la base de la Encuesta de Caracterización Socioeconómica Nacional (CASEN) 2013.

Cuadro A1.3

Estimación de parámetros trabajos de plazo fijo

\begin{tabular}{lcccrc}
\hline Clúster & $\mathbf{N}$ & $\begin{array}{c}\text { Estimación puntual } \\
\text { de la proporción } \\
\text { (en porcentajes) }\end{array}$ & $\begin{array}{c}\text { Desviación estándar } \\
\text { (en porcentajes) }\end{array}$ & \multicolumn{2}{c}{$\begin{array}{c}95 \% \text { de intervalo de confianza } \\
\text { (en porcentajes) }\end{array}$} \\
\cline { 5 - 7 } PIII & 568907 & 21,45 & 41,05 & Inferior & Superior \\
\hline PAIP & 359923 & 6,53 & 24,71 & 6,45 & 6,61 \\
\hline PISE & 2250517 & 16,25 & 36,90 & 16,21 & 16,30 \\
\hline PEAS & 876645 & 6,55 & 24,73 & 6,49 & 6,60 \\
\hline PEIS & 693361 & 76,56 & 42,36 & 76,47 & 76,66 \\
\hline PAIR & 747621 & 28,29 & 45,04 & 28,19 & 28,39 \\
\hline PAUV & 383109 & 0,24 & 4,90 & 0,22 & 0,26 \\
\hline PACUAS & 134118 & 0,81 & 8,99 & 0,77 & 0,86 \\
\hline PROSI & 1263558 & 9,91 & 29,89 & 9,86 & 9,97 \\
\hline
\end{tabular}

Fuente: Elaboración propia, sobre la base de la Encuesta de Caracterización Socioeconómica Nacional (CASEN) 2013.

Cuadro A1.4

Estimación de parámetros ausencia de contratos escritos

\begin{tabular}{lccccc}
\hline Clúster & $\mathbf{N}$ & $\begin{array}{c}\text { Estimación puntual } \\
\text { de la proporción } \\
\text { (en porcentajes) }\end{array}$ & $\begin{array}{c}\text { Desviación estándar } \\
\text { (en porcentajes) }\end{array}$ & \multicolumn{2}{c}{$\begin{array}{c}95 \% \text { de intervalo de confianza } \\
\text { (en porcentajes) }\end{array}$} \\
\cline { 5 - 7 } PIII & 568907 & 29,51 & 45,61 & Inferior & Superior \\
\hline PAIP & 359923 & 5,90 & 23,56 & 5,82 & 5,98 \\
\hline PISE & 2250517 & 3,81 & 19,15 & 3,79 & 3,84 \\
\hline PEAS & 876645 & 2,28 & 14,93 & 2,25 & 2,31 \\
\hline PEIS & 693361 & 35,13 & 47,74 & 35,02 & 35,24 \\
\hline PAIR & 747621 & 40,06 & 49,00 & 39,95 & 40,17 \\
\hline PAUV & 383109 & 0,29 & 5,41 & 0,28 & 0,31 \\
\hline PACUAS & 134118 & 0,95 & 9,72 & 0,90 & 1,00 \\
\hline PROSI & 1263558 & 3,37 & 18,04 & 3,34 & 3,40 \\
\hline
\end{tabular}

Fuente: Elaboración propia, sobre la base de la Encuesta de Caracterización Socioeconómica Nacional (CASEN) 2013. 
Cuadro A1.5

Estimación de parámetros subcontratación

\begin{tabular}{lccccc}
\hline Clúster & $\mathbf{N}$ & $\begin{array}{c}\text { Estimación puntual } \\
\text { de la proporción } \\
\text { (en porcentajes) }\end{array}$ & $\begin{array}{c}\text { Desviación estándar } \\
\text { (en porcentajes) }\end{array}$ & \multicolumn{2}{c}{$\begin{array}{c}\text { 95 de intervalo de confianza } \\
\text { (en porcentajes) }\end{array}$} \\
\cline { 6 - 7 } PIII & 568907 & 42,34 & 49,41 & Inferior & Superior \\
\hline PAIP & 359923 & 13,40 & 34,07 & 42,22 & 42,47 \\
\hline PISE & 2250517 & 3,63 & 18,71 & 3,61 & 3,66 \\
\hline PEAS & 876645 & 0,70 & 8,31 & 0,68 & 0,71 \\
\hline PEIS & 693361 & 46,76 & 49,90 & 46,65 & 46,88 \\
\hline PAIR & 747621 & 22,00 & 41,42 & 21,90 & 22,09 \\
\hline PAUV & 383109 & 53,83 & 49,85 & 53,67 & 53,98 \\
\hline PACUAS & 134118 & 11,93 & 32,42 & 11,76 & 12,11 \\
\hline PROSI & 1263558 & 2,04 & 14,13 & 2,01 & 2,06 \\
\hline
\end{tabular}

Fuente: Elaboración propia, sobre la base de la Encuesta de Caracterización Socioeconómica Nacional (CASEN) 2013.

Cuadro A1.6

Estimación de parámetros no afiliación previsional

\begin{tabular}{lccccc}
\hline Clúster & $\mathbf{N}$ & $\begin{array}{c}\text { Estimación puntual } \\
\text { de la proporción } \\
\text { (en porcentajes) }\end{array}$ & $\begin{array}{c}\text { Desviación estándar } \\
\text { (en porcentajes) }\end{array}$ & \multicolumn{2}{c}{$\begin{array}{c}\text { 95 de intervalo de confianza } \\
\text { (en porcentajes) }\end{array}$} \\
\cline { 6 - 7 } PIII & 568907 & 50,78 & 49,99 & 50,65 & 50,91 \\
\hline PAIP & 359923 & 32,81 & 46,95 & 32,66 & 32,96 \\
\hline PISE & 2250517 & 1,05 & 10,17 & 1,03 & 1,06 \\
\hline PEAS & 876645 & 0,99 & 9,91 & 0,97 & 1,01 \\
\hline PEIS & 693361 & 8,45 & 27,82 & 8,39 & 8,52 \\
\hline PAIR & 747621 & 24,92 & 43,26 & 24,83 & 25,02 \\
\hline PAUV & 383109 & 56,02 & 49,64 & 55,87 & 56,18 \\
\hline PACUAS & 134118 & 22,58 & 41,81 & 22,35 & 22,80 \\
\hline PROSI & 1263558 & 1,22 & 11,00 & 1,21 & 1,24 \\
\hline
\end{tabular}

Fuente: Elaboración propia, sobre la base de la Encuesta de Caracterización Socioeconómica Nacional (CASEN) 2013.

\section{Cuadro A1.7}

Estimación de parámetros afiliados previsionales que no cotizan

\begin{tabular}{lccccc}
\hline Clúster & $\mathbf{N}$ & $\begin{array}{c}\text { Estimación puntual } \\
\text { de la proporción } \\
\text { (en porcentajes) }\end{array}$ & $\begin{array}{c}\text { Desviación estándar } \\
\text { (en porcentajes) }\end{array}$ & \multicolumn{2}{c}{$\begin{array}{c}\text { 95\% de intervalo de confianza } \\
\text { (en porcentajes) }\end{array}$} \\
\cline { 5 - 7 } PIII & 568907 & 41,71 & 49,31 & Inferior & Superior \\
\hline PAIP & 359923 & 32,41 & 46,80 & 31,59 & 41,84 \\
\hline PISE & 2250517 & 2,91 & 16,82 & 2,25 & 32,56 \\
\hline PEAS & 876645 & 1,99 & 13,98 & 1,96 & 2,93 \\
\hline PEIS & 693361 & 19,19 & 39,38 & 19,09 & 19,28 \\
\hline PAIR & 747621 & 41,72 & 49,31 & 41,61 & 41,83 \\
\hline PAUV & 383109 & 37,77 & 48,48 & 37,61 & 37,92 \\
\hline PACUAS & 134118 & 19,89 & 39,92 & 19,68 & 20,10 \\
\hline PROSI & 1263558 & 3,90 & 19,35 & 3,86 & 3,93 \\
\hline
\end{tabular}

Fuente: Elaboración propia, sobre la base de la Encuesta de Caracterización Socioeconómica Nacional (CASEN) 2013. 
Cuadro A1.8

Estimación de parámetros sin afiliación a sistema de salud

\begin{tabular}{lccccc}
\hline Clúster & $\mathrm{N}$ & $\begin{array}{c}\text { Estimación puntual } \\
\text { de la proporción } \\
\text { (en porcentajes) }\end{array}$ & $\begin{array}{c}\text { Desviación estándar } \\
\text { (en porcentajes) }\end{array}$ & \multicolumn{2}{c}{$\begin{array}{c}95 \% \text { de intervalo de confianza } \\
\text { (en porcentajes) }\end{array}$} \\
\cline { 5 - 7 } PIII & 568907 & 6,51 & 24,66 & Inferior & Superior \\
\hline PAIP & 359923 & 13,24 & 33,89 & 13,13 & 6,57 \\
\hline PISE & 2250517 & 0,50 & 7,05 & 0,49 & 0,51 \\
\hline PEAS & 876645 & 0,55 & 7,42 & 0,54 & 0,57 \\
\hline PEIS & 693361 & 2,91 & 16,80 & 2,87 & 2,95 \\
\hline PAIR & 747621 & 7,44 & 26,24 & 7,38 & 7,50 \\
\hline PAUV & 383109 & 5,15 & 22,10 & 5,08 & 5,22 \\
\hline PACUAS & 134118 & 7,27 & 25,97 & 7,14 & 7,41 \\
\hline PROSI & 1263558 & 1,29 & 11,28 & 1,27 & 1,31 \\
\hline
\end{tabular}

Fuente: Elaboración propia, sobre la base de la Encuesta de Caracterización Socioeconómica Nacional (CASEN) 2013.

Cuadro A1.9

Estimación de parámetros media de ingresos del trabajo

\begin{tabular}{lrrrrr}
\hline \multirow{2}{*}{ Clúster } & $\mathrm{N}$ & $\begin{array}{c}\text { Estimación puntual } \\
\text { de la Media }\end{array}$ & Desviación estándar & \multicolumn{2}{c}{$95 \%$ de intervalo de confianza } \\
\cline { 5 - 6 } PIII & 551355 & 156790 & 119834 & 156474 & 157106 \\
\hline PAIP & 338834 & 470009 & 402979 & 468652 & 471366 \\
\hline PISE & 2225037 & 280413 & 105838 & 280274 & 280552 \\
\hline PEAS & 874723 & 1386631 & 1344898 & 1383812 & 1389449 \\
\hline PEIS & 664417 & 221514 & 52453 & 221388 & 221640 \\
\hline PAIR & 718468 & 217396 & 127915 & 217100 & 217692 \\
\hline PAUV & 361915 & 78191 & 78014 & 77937 & 78446 \\
\hline PACUAS & 131587 & 1688940 & 1487077 & 1680906 & 1696975 \\
\hline PROSI & 1247400 & 513347 & 312763 & 512798 & 513896 \\
\hline
\end{tabular}

Fuente: Elaboración propia, sobre la base de la Encuesta de Caracterización Socioeconómica Nacional (CASEN) 2013.

Cuadro A1.10

Estimación de parámetros lugares de trabajo atípicos

\begin{tabular}{lccccc}
\hline Clúster & $\mathrm{N}$ & $\begin{array}{c}\text { Estimación puntual } \\
\text { de la proporción } \\
\text { (en porcentajes) }\end{array}$ & $\begin{array}{c}\text { Desviación estándar } \\
\text { (en porcentajes) }\end{array}$ & \multicolumn{2}{c}{$\begin{array}{c}95 \% \text { de intervalo de confianza } \\
\text { (en porcentajes) }\end{array}$} \\
\cline { 5 - 6 } PIII & 568907 & 86,16 & 34,53 & Inferior & Superior \\
\hline PAIP & 359923 & 65,27 & 47,61 & 86,07 & 86,25 \\
\hline PISE & 2250517 & 26,81 & 44,30 & 26,75 & 26,87 \\
\hline PEAS & 876645 & 13,92 & 34,62 & 13,85 & 14,00 \\
\hline PEIS & 693361 & 70,22 & 45,73 & 70,11 & 70,32 \\
\hline PAIR & 747621 & 60,04 & 48,98 & 59,93 & 60,15 \\
\hline PAUV & 383109 & 91,89 & 27,30 & 91,80 & 91,98 \\
\hline PACUAS & 134118 & 49,97 & 50,00 & 49,70 & 50,23 \\
\hline PROSI & 1263558 & 22,61 & 41,83 & 22,54 & 22,68
\end{tabular}

Fuente: Elaboración propia, sobre la base de la Encuesta de Caracterización Socioeconómica Nacional (CASEN) 2013. 


\section{Cuadro A1.11}

Estimación de parámetros enfermedades o accidentes por motivos laborales

\begin{tabular}{lccccc}
\hline Clúster & $\mathbf{N}$ & $\begin{array}{c}\text { Estimación puntual } \\
\text { de la proporción } \\
\text { (en porcentajes) }\end{array}$ & $\begin{array}{c}\text { Desviación estándar } \\
\text { (en porcentajes) }\end{array}$ & \multicolumn{2}{c}{$\begin{array}{c}95 \% \text { de intervalo de confianza } \\
\text { (en porcentajes) }\end{array}$} \\
\cline { 5 - 7 } PIII & 568907 & 3,11 & 17,37 & Inferior & Superior \\
\hline PAIP & 359923 & 2,89 & 16,75 & 2,83 & 3,16 \\
\hline PISE & 2250517 & 3,99 & 19,57 & 3,96 & 4,01 \\
\hline PEAS & 876645 & 4,29 & 20,26 & 4,25 & 4,33 \\
\hline PEIS & 693361 & 3,08 & 17,28 & 3,04 & 3,12 \\
\hline PAIR & 747621 & 2,92 & 16,85 & 2,89 & 2,96 \\
\hline PAUV & 383109 & 3,29 & 17,84 & 3,23 & 3,35 \\
\hline PACUAS & 134118 & 3,64 & 18,74 & 3,54 & 3,74 \\
\hline PROSI & 1263558 & 3,91 & 19,37 & 3,87 & 3,94 \\
\hline
\end{tabular}

Fuente: Elaboración propia, sobre la base de la Encuesta de Caracterización Socioeconómica Nacional (CASEN) 2013.

\section{Cuadro A1.12}

Estimación de parámetros media de horas semanales

\begin{tabular}{lccccc}
\hline Clúster & $\mathbf{N}$ & $\begin{array}{c}\text { Estimación puntual } \\
\text { de la media } \\
\text { (en porcentajes) }\end{array}$ & $\begin{array}{c}\text { Desviación estándar } \\
\text { (en porcentajes) }\end{array}$ & \multicolumn{2}{c}{$\begin{array}{c}\text { 95\% de intervalo de confianza } \\
\text { (en porcentajes) }\end{array}$} \\
\cline { 5 - 7 } PIII & 568907 & 40,7 & 85,1 & Inferior & Superior \\
\hline PAIP & 359923 & 50,0 & 86,4 & 40,5 & 40,9 \\
\hline PISE & 2250517 & 46,5 & 39,0 & 46,7 & 50,3 \\
\hline PEAS & 876645 & 47,9 & 58,4 & 47,7 & 46,5 \\
\hline PEIS & 693361 & 46,1 & 39,4 & 46,0 & 46,0 \\
\hline PAIR & 747621 & 45,1 & 72,8 & 45,0 & 45,3 \\
\hline PAUV & 383109 & 38,1 & 118,5 & 37,7 & 38,5 \\
\hline PACUAS & 134118 & 46,1 & 58,9 & 45,8 & 46,4 \\
\hline PROSI & 1263558 & 48,4 & 59,0 & 48,3 & 48,5 \\
\hline
\end{tabular}

Fuente: Elaboración propia, sobre la base de la Encuesta de Caracterización Socioeconómica Nacional (CASEN) 2013. 